\title{
A cultura da quarta dimensão no final do século XIX e início do século XX: um conceito para além do espaço-tempo de Einstein-Minkowski
}

Washington Luiz Raposo ${ }^{1}$

Doutorando do Programa de Pós-Graduação em Ciência, Tecnologia

e Educação" - CEFET/RJ

Centro Federal de Educação Tecnológica Celso Suckow da Fonseca

Nova Friburgo - RJ

José Claudio Reis ${ }^{1}$

Programa de Pós-Graduação em Ciência, Tecnologia

e Educação" - CEFET/RJ

Universidade do Estado do Rio de Janeiro

Rio de Janeiro - RJ

\section{Resumo}

Ao final do Séc. XIX e no início do Séc. XX, existia no meio cultural um outro entendimento sobre o conceito de quarta dimensão que não era o de uma dimensão temporal como entendemos hoje, baseada na teoria de Einstein-Minkowski. Nessa concepção, de cunho mais filosófico/místico, a quarta dimensão representava uma dimensão extrassensivel do espaço. O entendimento de que o espaço possui mais de três dimensões, as três conhecidas e mais a quarta dimensão extra-sensorial, exerceu forte influência sobre diversas áreas da cultura e, segundo Henderson (2013), teve papel importante nas artes e na literatura de ficção cientifica desse período. Estas discussões apresentadas fazem parte de um material didático elaborado para ser utilizado em uma disciplina regular de Física Moderna de um curso de licenciatura em física, a ser ministrada no primeiro semestre de 2020. No presente trabalho, apresentaremos as linhas gerais da proposta didática que será aplicada nesse curso, ainda em estágio de elaboração, e também apresentaremos uma síntese de três textos elaborados para esta disciplina. Estes textos, que tratam do

\footnotetext{
${ }^{+}$Fourth-dimensional culture in the late nineteenth and early twentieth centuries: a concept beyond EinsteinMinkowski's spacetime

* Recebido: novembro de 2019. Aceito: junho de 2020.

${ }^{1}$ E-mails: raposo.cefetrj@gmail.com; joseclaudioreis63@gmail.com
} 
contexto da elaboração do conceito de quarta dimensão na virada do século $X X$, compõem um total de cinco textos didáticos direcionados aos alunos dessa disciplina. Os demais dois textos que faltam estão em preparo e irão compor o material didático, juntamente com outros recursos a serem utilizados na disciplina mencionada. Quanto ao presente trabalho, iniciamos discutindo o arcabouço teórico necessário para a elaboração dos textos, depois discutimos alguns registos antecedentes ao século XIX que tratarão do assunto da dimensionalidade do espaço. A seguir passamos para uma apresentação sucinta da teoria do espaço-tempo de Einstein-Minkowski e, por fim, apresentamos as linhas gerais de uma concepção "alternativa" de quarta dimensão existente na virada do século em questão. Por fim, tratamos da proposta de abordagem interdisciplinar mencionada, que é uma disciplina obrigatória do currículo de licenciatura em Física de uma instituição federal de ensino.

Palavras-chave: Filosofia da Quarta Dimensão; Física; Cultura.

\begin{abstract}
In the late nineteenth and early twentieth centuries, there was in the cultural milieu another understanding of the concept of the fourth dimension which was not that of a temporal dimension as we understand it today, based on the theory of Einstein-Minkowski. In this more philosophical/mystical conception, the fourth dimension represented an extra-sensitive dimension of space. The understanding that space has more than three dimensions, the three known and plus the fourth extrasensory dimension, had a strong influence on various areas of culture and, according to Henderson (2013), played an important role in the arts and fiction literature of this period. These discussions presented are part of a didactic material designed to be used in a regular discipline of Modern Physics 1 of a degree course in physics, to be taught in the first semester of 2020. In the present work, we will present the general lines of the didactic proposal that will be applied in this course, still in its elaboration stage, and we will also present a synthesis of three texts elaborated for this discipline. These texts, which deal with the context of the elaboration of the fourth dimension concept at the turn of the twentieth century, make up a total of six didactic texts directed to the students of this discipline. The remaining three missing texts are in preparation and will compose the didactic material, along with other
\end{abstract}


resources to be used in the mentioned discipline. As for the present work, we start by discussing the theoretical framework necessary for the elaboration of the texts, then we discuss some records before the nineteenth century that will deal with the subject of space dimensionality. We then move on to a succinct presentation of Einstein-Minkowski's theory of space-time and, finally, present the outline of a fourthdimensional "alternative" conception at the turn of the century in question. Finally we deal with the proposed interdisciplinary approach mentioned, which is a compulsory subject of the Physics degree curriculum of a federal educational institution.

Keywords: Fourth Dimensional Philosophy; Physics; Culture.

\section{Introdução}

O entendimento de que vivemos em um mundo em quatro dimensões, três espaciais e uma dimensão temporal, já está bem inserido na concepção de mundo atual. A ideia de que a quarta dimensão é a dimensão do tempo nos parece até bem óbvia, no entanto, isso se deve ao fato de que este foi o conceito que predominou na ciência e se colocou como consensual sobre a cultura em geral. Vale ressaltar que os conceitos de tempo e de espaço foram objeto de uma longa "batalha" intelectual a respeito de seus significados e suas características, ao longo da história (REIS; REIS, 2016).

A própria noção de que o tempo seria a quarta dimensão não foi sempre tão óbvia assim. A partir da segunda metade do século XIX e início do século XX, a concepção de que existia uma quarta dimensão espacial extra-sensorial, não tangível à capacidade de percepção humana, se tornou bastante difundida e influente, principalmente nos meios artísticos e filosóficos. Segundo Henderson (2013), é possível perceber seu impacto cultural, nesse período, na literatura de ficção científica, nas artes plásticas e em uma filosofia "popular", denominada de Filosofia do Hiperespaço.

Não há dúvidas de que dois ramos da matemática atuaram como grandes motivadores das discussões a respeito da quantidade de dimensões possíveis. Primeiramente, temos o desenvolvimento das geometrias não-euclidianas, com seus passos iniciais durante a primeira metade do século XIX, e, logo em seguida, os desdobramentos das possibilidades espaciais da geometria n-dimensional. Esta última teve suas primeiras discussões publicadas na década de 1840, mas se consolidou de fato durante as últimas décadas do mesmo século.

As geometrias não-euclidianas foram uma consequência das tentativas de demonstração, ou solução, para o problemático quinto postulado de Euclides (EVES, 1992). Em seu livro, "Os Elementos" (ou apenas "Elementos"), Euclides apresenta cinco 
postulados $^{2}$, ou regras fundamentais da geometria, onde os quatro primeiros postulados são bastante evidentes e intuitivos. No entanto, o quinto postulado, não gozava da mesma clareza e evidência intuitiva.

Talvez, por estarmos muito ambientados com a geometria de Euclides, não nos seja compreensível, de imediato, o porquê desse postulado ser tão controverso. Na verdade, ele pode parecer até muito "óbvio".

Entretanto, se considerarmos os axiomas da geometria como abstrações da experiência, podemos ver uma diferença entre esse postulado e os outros quatro. Os dois primeiros postulados são abstrações de nossas experiências, desenhando com uma régua; o terceiro postulado deriva de nossas experiências desenhando com um compasso. O quarto postulado é talvez menos óbvio como uma abstração, no entanto, deriva de nossas experiências com a medição de ângulos com um transferidor (em que a soma dos ângulos suplementares é de $180^{\circ}$, de modo que, se os ângulos complementares forem congruentes entre si, eles devem medir $90^{\circ}$ cada um). O quinto postulado é diferente porque não podemos verificar empiricamente se duas linhas se encontram, já que podemos desenhar apenas segmentos, não linhas. Podemos estender os segmentos mais e mais para ver se eles se encontram, mas não podemos continuar estendendo-os para sempre. Nosso único recurso é verificar o paralelismo indiretamente, usando outros critérios além da definição (GREENBERG, 1994, p. 19-20) (Tradução nossa).

Greenberg (1994) continua sua argumentação afirmando que um postulado deve, originalmente, ser tão simples e intuitivo que ninguém poderia duvidar de sua validade, entretanto, desde a antiguidade o quinto postulado foi motivo de dúvida. Devido a sua maior complexidade e por carecer da mesma evidência intuitiva presente nos outros quatro, o quinto postulado, ou postulado das paralelas, atraiu a atenção dos geômetras e foi alvo de tentativas de demonstração ou de substituição por séculos (GREENBERG, 1994). Embora as sementes das geometrias não-euclidianas já viessem sendo cultivadas, pelos diversos geômetras que tentaram demonstrar o postulado das paralelas, dois personagens se tornaram emblemáticos ao apresentarem outras possibilidades geométricas. Foram eles, Janos (Johann) Bolyai (18021860) e Nikolai Lobachevsky (1792-1856) (ROSENFELD, 1988).

Já a geometria n-dimensional surgiu, gradualmente, como uma extensão natural da geometria analítica, entretanto, a impossibilidade de se visualizar geometricamente dimensões superiores a três (eixos $\mathrm{x}, \mathrm{y}$ e $\mathrm{z}$ ) significava um dificultador para representações mais concretas do seu objeto de estudo. Até a década de 1870 a geometria n-dimensional

\footnotetext{
${ }^{2}$ Os cinco postulados fundamentais de Euclides são: $1^{\circ}$ - Dados dois pontos distintos, há um único segmento de reta que os une; $2^{\circ}$ - Um segmento de reta pode ser prolongado indefinidamente para construir uma reta; $3^{\circ}$ Dados um ponto qualquer e uma distância qualquer, pode-se construir uma circunferência de centro naquele ponto e com raio igual à distância dada; $4^{\circ}$ - Todos os ângulos retos são congruentes; $5^{\circ}$ - Se duas linhas são intersectadas por uma terceira linha de tal forma que a soma dos ângulos internos em um lado é menor que dois ângulos retos, então as duas linhas, se forem estendidas indefinidamente, devem se intersectar em algum ponto neste lado. (EUCLIDES, 2009)
} 
permaneceu como um acessório para outras pesquisas geométricas. Foi em 1870 que Arthur Cayley (1821-1895) estabeleceu seus princípios gerais da geometria n-dimensional e, em 1881, Giuseppe Veronese (1854-1917) empregou os métodos da geometria sintética para ndimensões, marcando uma mudança em direção a representações mais concretas (HENDERSON, 2013).

Com estas duas vertentes matemáticas, o exame da natureza do nosso espaço englobou duas importantes questões: (1) a possível curvatura do espaço, sugerida pelas geometrias não-euclidianas e o problema dos axiomas da geometria; (2) o número de dimensões do espaço, sugerido pelas geometrias n-dimensionais. Um grande divulgador destas ideias foi Hermann von Helmholtz, através de textos populares sobre os axiomas da geometria e a possível curvatura do espaço. Os artigos de Helmholtz, publicados na Alemanha, Inglaterra, França e nos Estados Unidos, atraíram a atenção entre os anos 1860 e 1870 (HENDERSON, 2013).

O surgimento das geometrias não-euclidianas trouxe consigo questões importantes para a filosofia da ciência e da matemática. Até então, a geometria de Euclides era considerada como a única possível e, por isso, uma forma segura de se representar a realidade. A própria mecânica de Newton repousava sobre tal sistema geométrico. Em sua obra, "Princípios Matemáticos de Filosofia Natural", Newton apresenta as suas definições para o tempo e para o espaço e atribui ao espaço a qualidade de ser absoluto e euclidiano (JAMMER, 2010).

Outro impasse importante, gerado pelas geometrias não-euclidianas, diz respeito às concepções epistemológicas e ao conceito de espaço defendidos por Emmanuel Kant, filósofo que exerceu grande influência no século XIX. Ele explorou ao máximo o conhecimento geométrico em todos os pontos essenciais do seu "Idealismo Transcendental" (CAMPOS, 2016).

Para Kant, a geometria euclidiana era o paradigma de conhecimento sintético a priori $^{3}$ e serviu de base para suas argumentações sobre teoria do conhecimento. Sua concepção de espaço, assim como o número de dimensões deste espaço, também é resultante da característica única e irrefutável da geometria de Euclides, uma vez que era a única conhecida em seu tempo.

Kant também enfatizou a certeza e a necessidade das proposições geométricas estarem ligadas a um espaço com somente três dimensões e que estas não podem ser juízos $a$ posteriori, empíricos, mas juízos a priori.

\footnotetext{
${ }^{3}$ De forma muitíssimo sucinta, para Kant, os juízos analíticos seriam as qualidades inerentes e evidentes ao sujeito em análise e, por isso, pertencentes ao conceito atribuído ao próprio sujeito. Eles são importantes e necessários, mas só para conseguir a clareza nos conceitos. Os juízos sintéticos são ampliativos, são conhecimentos que derivam do conceito, mas não são parte dele, são ampliações do conhecimento sobre o sujeito. Já o conhecimento a priori é aquele que independe da experiência sensível, ao contrário do conhecimento a posteriori que tem origem na experiência (MORA, 2001). Desta forma, sintético a priori seria o conhecimento que não resulta da experiência sensível, mas que é maior que o próprio conceito do objeto de estudo, que amplia o conhecimento sobre ele.
} 
A geometria é uma ciência que determina as propriedades do espaço de maneira sintética, mas também a priori. O que tem de ser então a representação do espaço, para que seja possivel tal conhecimento? Ele tem de ser originariamente uma intuição; pois a partir de um mero conceito não podem ser extraidas proposições que vão além do conceito, tal como, no entanto, ocorre na geometria (Introdução, V). Mas esta intuição tem de encontrar-se em nós a priori, i. e., antes de qualquer percepção de um objeto, e tem, portanto, de ser pura, não empirica. Pois as proposições geométricas são todas apodíticas, i. e., ligadas à consciência de sua necessidade, como, por exemplo, em "o espaço tem apenas três dimensões"; tais proposições, contudo, não podem ser juizos empíricos ou de experiência, nem ser a partir deles inferidas (Introdução, II) (KANT, 2018, p. 75-76).

Com o desenvolvimento das geometrias não euclidianas, foram inevitáveis os ataques aos aspectos geométrico-espaciais da obra de Kant e as dúvidas suscitadas, no meio filosófico, ao seu monumental trabalho. O principal alvo das críticas era a tese de que as propriedades do espaço são determinadas de forma sintética a priori pela geometria (CAMPOS, 2016).

Juntamente com as geometrias não-euclidianas e a geometria n-dimensional, surgiram muitas questões sem resposta imediata. A própria mecânica Newtoniana, que era considerada como "verdadeira", suscitou dúvidas e gerou o questionamento sobre a possibilidade de existência de outras mecânicas para outros espaços (não-euclidianos) (SILVA, 2006).

Este é, em linhas gerais, o estado das coisas em decorrência das inovações matemáticas das geometrias não-euclidianas e das geometrias n-dimensionais. Com a popularização destas ideias nos meios não acadêmicos, especificamente não físicomatemáticos, uma série de especulações a respeito de dimensões superiores da existência, de cunho mais filosófico ou místico, começou a brotar em diversas outras áreas do conhecimento.

Em sintonia com a insatisfação crescente com o materialismo e com o positivismo, o conceito de "quarta dimensão" surgiu como uma espécie de "evidência" de uma existência superior, de algo que está além da capacidade de percepção humana. Essas ideias deram origem a sistemas filosóficos idealistas e místicos, como os de Charles Hinton (1853-1907), que transformou a teoria matemática da "quarta dimensão" em uma estrutura filosófica; Claude Bragdon (1866-1946) e Peter Ouspensky (1878-1947), que estabeleceram correspondência entre o conceito de quarta dimensão e crenças teosóficas e ocultistas (HENDERSON, 2013).

Diversas questões que não eram bem entendidas na época, tanto na ciência como nas religiões e no ocultismo, tendiam a ser explicadas pela existência desta quarta dimensão. Inúmeras especulações a respeito do átomo, do éter, da abrangência dos fenômenos eletromagnéticos, da gravidade etc., foram elaboradas em termos da quarta dimensão (HENDERSON, 2013). A própria localização do paraíso judaico-cristão e mesmo os 
fenômenos mediúnicos, muito populares na Europa do século XIX, apresentaram tentativas de explicação através da existência da quarta dimensão espacial (HENDERSON, 2013; FERREIRA, 2008).

Nos meios culturais, não voltados para o academicismo científico, como a literatura, a música e as artes plásticas, a quarta dimensão e as geometrias não-euclidianas significaram novos meios de entender e representar o mundo. Elas tiveram um efeito libertador para estes artistas. Eles sentiram que não precisavam mais estar presos às regras da geometria de Euclides, da perspectiva linear renascentista ou mesmo da representação do mundo tal qual observamos (HENDERSON, 2013). O impacto da "quarta dimensão" foi muito abrangente, talvez só comparável ao alcance popular da Teoria da Relatividade Geral, após 1919.

Foi logo após a teoria de Einstein ser corroborada pelo experimento do desvio da luz ao passar pelo Sol, durante o eclipse solar de $1919,{ }^{4}$ que o nome de Einstein se popularizou de forma excepcional e a Teoria da Relatividade se tornou interessante ao público leigo, mesmo que poucos a entendessem de fato.

Com a publicação em jornais de todo o mundo, sobre a importante descoberta, as concepções sobre o espaço-tempo, ao qual a quarta dimensão é o tempo, ganharam notoriedade entre o público em geral. Este fato, em certa medida, trouxe significativa redução do interesse popular sobre as especulações a respeito de dimensões espaciais mais elevadas e colocou em evidência a noção do tempo como a quarta dimensão (HENDERSON, 2013).

Mas, de que se trata esta Filosofia do Hiperespaço? Quais as principais ideias defendidas? Em que medida ela impactou as demais vertentes da cultura de sua época? E ainda, de que forma estas discussões podem ser apresentadas aos alunos que estudam a Teoria da Relatividade para que enriqueçam suas visões sobre a ciência e sobre o envolvimento desta com as demais áreas da cultura humana? Estas são as questões principais a serem discutidas neste trabalho, que tem dois propósitos interligados, mas distintos. O primeiro propósito é o de delinear melhor a concepção de espaço e de quarta dimensão presentes no período em discussão. Com isso, buscamos evidenciar que a concepção do tempo como a quarta dimensão, do continuum espaço-tempo, não foi a única existente ao final do século XIX e início do XX, apresentando assim um contexto de época muito mais amplo e complexo sobre o tema. Estas discussões nos conduzem a reforçar a visão da ciência como estando sempre

\footnotetext{
${ }^{4}$ O amplo projeto promovido pela Royal Astronomical Society of London, que tinha como propósito realizar o teste experimental da Teoria da Relatividade Geral, ocorreu durante o eclipse solar de 29 de maio de 1919. Este empreendimento destacou equipes de astrônomos para duas cidades em países da região sul do globo, onde o fenômeno seria melhor observado. A equipe que fez as observações na ilha do Príncipe (em São Tomé e Príncipe, costa da África) foi chefiada pelo astrônomo Sir Arthur Eddington (1882-1944), acompanhado de Edwin Cottingham (1869-1940), a outra equipe se dirigiu à cidade de Sobral (no Ceará, aqui no Brasil), e contou com os astrônomos Andrew Crommelin (1865-1939) e Charles Davidson (1875-1970). Uma discussão bastante interessante sobre este experimento, além de toda a campanha publicitária e as articulações ocorridas para a realização do mesmo e sua divulgação, podem ser encontradas em: VIDEIRA, A. A. Einstein e o Eclipse de 1919. Física na Escola, v. 6, n. 1, p. 83-87, 2005.
} 
inserida em um contexto sociocultural mais amplo, nunca isolada em laboratórios ou gabinetes de pesquisa (REIS; GUERRA; BRAGA, 2006).

O segundo propósito deste trabalho é o de apresentar as linhas gerais de uma proposta didática, em fase de elaboração, que será utilizada em uma disciplina de Física Moderna 1, do curso de licenciatura em Física de uma instituição de ensino superior de uma cidade do interior do Estado do Rio de Janeiro, no primeiro semestre de 2020. Esta proposta didática está vinculada a uma tese de doutorado, em andamento, de um Programa de Pósgraduação em Ensino de Ciências.

Toda a primeira parte deste trabalho, tópicos 3,4 e 5, representa a síntese de três textos didáticos elaborados para os alunos da disciplina mencionada. Estes textos foram sintetizados, no presente trabalho, para melhor adequar o assunto às dimensões exigidas para um artigo, mas esta síntese está resumindo perfeitamente o teor dos três textos. As diferenças residem apenas em alguns detalhamentos mais estendidos de algumas partes, para facilitar a compreensão por parte dos alunos.

Outros dois textos estão em fase de preparação e irão compor a proposta didática para o curso em questão. Iremos somar a estes textos outros recursos didáticos, como apresentações em "slides" referentes a cada tema, vídeos disponibilizados nas plataformas de compartilhamento digital, simulações e demonstrações encontradas em portais educacionais, como os do portal Phet Colorado ${ }^{5}$, por exemplo.

Estes textos em elaboração versarão sobre a literatura de ficção científica do século XIX, as vanguardas europeias do início do século $\mathrm{XX}$ e as implicações culturais da popularização da Teoria da Relatividade de Einstein.

No tópico II deste trabalho, discutiremos os referenciais metodológicos que guiaram a transposição didática dos textos de História da Ciência e História da arte para o recorte histórico que elaboramos.

Nos tópicos seguintes, apresentaremos um breve relato das primeiras discussões sobre dimensões do espaço e um rápido apanhado do trabalho de Lorentz e Poincaré, passando, em seguida, para as linhas gerais do conceito de espaço-tempo de EinsteinMinkowski. Após, apresentaremos a concepção espacial da quarta dimensão, da Filosofia do Hiperespaço. Finalmente, no último tópico deste trabalho, discutiremos melhor os pormenores da proposta didática, apresentaremos os objetivos e expectativas para esta disciplina, que é uma disciplina obrigatória desse curso de licenciatura em Física, e faremos nossas considerações gerais.

\footnotetext{
${ }^{5}$ Portal de simulações para o ensino de ciências, Phet Colorado. Disponível em:

$<$ https://phet.colorado.edu/pt_BR/simulations/category/physics>. Acesso em: 25 out. 2019.
} 


\section{Metodologia de transposição didática dos textos de História da Ciência}

Os textos a que nos referimos, tanto a síntese que aqui apresentamos quanto os que estão em preparo, estão direcionados para a abordagem histórico-filosófica do ensino de ciências, que aqui repousa sobre o entendimento da ciência como construção sociocultural da humanidade (GUERRA; REIS; BRAGA, 2013). Eles representam nossa intenção de tratar um tema amplo e complexo, mas em linguagem compatível com as capacidades de alunos de graduação em Física.

Outro ponto importante a ser mencionado é que os textos, apesar de serem originais, não representam contribuições novas para a área da História da Ciência, mas sim para o ensino de ciências com enfoque na História e Filosofia da Ciência (HFC). Nosso objetivo é trazer uma narrativa histórica adequada, em termos historiográficos e didáticos, ao contexto da formação de professores de Física, concordando e respondendo aos apontamentos de Martins (2007), sobre a dificuldade de encontrar material didático adequado para a abordagem de HFC no ensino. Esse aspecto, a qualidade dos materiais produzidos para fins didáticos, de divulgação científica e popularização da História da Ciência, é frequentemente apontado como problemático (MARTINS, 1998; MARTINS, 2014). Muitos dos textos elaborados para estas finalidades não apresentam a qualidade historiográfica necessária para uma boa abordagem dos temas de HFC, representando assim um desserviço à educação científica (MARTINS, 2014).

Tendo em vista estes apontamentos e buscando não incorrer nos mesmos problemas descritos, tomamos como ponto de partida, elencar os parâmetros fundamentais para produção de textos que fossem adequados para o uso didático, mas que mantivessem a qualidade historiográfica necessária.

Elencamos três parâmetros, bastante amplos, para que possamos produzir textos adequados para o propósito.

O primeiro parâmetro é o de evitar fortemente a construção das narrativas que reforçam uma visão linear, simplista, elitista, neutra e ingênua da ciência, produtora de provas irrefutáveis, apoiadas em um suposto método científico universal. (MCCOMAS et al., 1998; GIL PÉREZ; MONTORO et al., 2001; MOURA; GUERRA, 2016)

O segundo parâmetro é o de evitar fortemente narrativas anacrônicas ${ }^{6}$, ou seja, que interpretam e julgam os acontecimentos históricos baseando-se em valores, ideias e crenças que não os do contexto original. (FORATO; MARTINS; PIETROCOLA, 2009)

\footnotetext{
${ }^{6}$ A narrativa anacrônica acaba olhando para o passado de forma preconceituosa e descontextualizada, enaltecendo determinados aspectos e ideias e ignorando outros aspectos que poderiam ser tão importantes, ou até mais importantes, que os escolhidos. Tomando como exemplos mais comuns de anacronismo temos o "whigguismo", que narra os acontecimentos com o propósito de afirmar a superioridade ou autoridade de determinados indivíduos, entidades ou instituições. Um tipo especial de "whiggismo", muito comum, é o "hagiografia". Este anacronismo romantiza certos pensadores da ciência como heróis, ou gênios, reduzindo a importância ou ridicularizando seus opositores. Temos ainda a reconstrução linear de episódios da História da Ciência, que entende a ciência como uma construção racional e que se desenvolve do mais primitivo para o mais sofisticado, sem saltos, retomadas, percalços ou controvérsias (FORATO; MARTINS; PIETROCOLA, 2009).
} 
O terceiro parâmetro é o de valorizar a importância do contexto social na construção da ciência, explorando as contribuições de outras formas de conhecimento como as artes, os ofícios práticos, as questões religiosas e místicas, etc. (REIS; GUERRA; BRAGA, 2006), buscando compreender as concepções científicas do passado em seu contexto, e não como "precursoras" das ideias do presente (SCHMIEDECKE; PORTO, 2014; GUERRA; REIS; BRAGA, 2013).

Nós nos apoiamos, também, nas recomendações apontadas por Martins (2005), que apresenta importantes critérios historiográficos a serem adotados na descrição de episódios históricos.

Outro aspecto importante a ser considerado diz respeito aos requisitos que devem ser observados nas transposições didáticas (CHEVALLARD, 1991) das áreas científicas, no nosso caso da História da Ciência, para transformar em conteúdos adequados à educação, o que representa uma mudança de nicho epistemológico (FORATO; MARTINS; PIETROCOLA, 2009). Para tal empreendimento devemos reconhecer com clareza as diferentes funções sociais dos textos historiográficos e dos textos educacionais.

Procuramos, assim, superar a persistente dicotomia entre internalismo e externalismo, focamos o olhar para o contexto em que se desenvolveram os conhecimentos científicos, mas sem perdermos de vista a importância dos desenvolvimentos internos e próprios da ciência. Buscamos contrapor as fontes secundárias de leitura com as fontes primárias, para construir uma narrativa condizente com os critérios mencionados, e perseguimos um ideal de clareza didática para nossa escrita, uma vez que serão textos lidos por alunos de Física e não por indivíduos familiarizados com a linguagem de HFC.

\section{As discussões sobre as dimensões do espaço antes do século XIX}

Para uma melhor compreensão do trabalho de Minkowski e do conceito de quarta dimensão que queremos apresentar nessa seção, faz-se necessária uma rápida digressão sobre o tema, para antes das realizações de Lorentz, Poincaré e Einstein.

Muito antes destes pesquisadores começarem suas vidas acadêmicas, a ideia de tempo como uma quarta dimensão já havia aparecido nos meios matemáticos, mas sem maior aprofundamento teórico ou especulativo quanto a sua existência física.

De acordo com Henderson (2013), a questão do espaço ser tridimensional remonta, pelo menos, a Aristóteles, que discutiu este assunto no De Caelo ${ }^{7}$. Leibniz também trata do tema, mas de forma superficial e geométrica apenas. No entanto, o primeiro uso real do termo quarta dimensão parece ter sido na Inglaterra do século XVII, no círculo platonista de Henry More, em Cambridge. Embora, a quarta dimensão descrita por More, de 1671, não fosse

\footnotetext{
${ }^{7}$ Sobre o céu (em latim, De Caelo) é o tratado cosmológico escrito por Aristóteles onde se encontra toda a sua teoria cosmológica. Nesse tratado, Aristóteles descreve os corpos celestes, os mundos supralunar e sublunar, a composição dos corpos, o seu movimento etc.
} 
realmente uma dimensão do espaço físico, mas sim a localização do ideal platônico (HENDERSON, 2013).

Segundo o matemático canadense Raymond Clare Archibald (1875-1955), em um curto artigo sobre o tema no "Bulletin of the American Mathematical Society" de 1914, o primeiro registro da relação do tempo com uma quarta dimensão ocorreu na famosa Enciclopédia Francesa, editada por Diderot (1713-1784) e d'Alembert (1717-1783), em 1754. Foi em um dos verbetes característicos da enciclopédia, intitulado de "Dimensão", que d'Alembert atribui ao tempo a qualidade de quarta dimensão. Nesse mesmo verbete, ele menciona que esta ideia se deve a "un homme d'esprit de ma connaisance" (um homem de inteligência que conheço). Acredita-se que esta seja uma referência à Lagrange (1736-1813), no entanto, não há elementos para comprovar que seja realmente uma referência a ele (ARCHIBALD, 1914).

Só em 1797 que Lagrange publicou um trabalho, intitulado de "Théorie des Donctions Analytiques" (Teoria das Funções Analíticas), onde se encontra a primeira referência explícita do tempo como quarta dimensão (ARCHIBALD, 1914). Mas, claramente, se trata de uma questão puramente teórico-matemática sem nenhuma referência à realidade Física.

\footnotetext{
Vamos usar a teoria das funções na mecânica, aqui as funções se referem essencialmente ao tempo, que sempre designaremos como $t$, e, como a posição de um ponto no espaço depende de três coordenadas retangulares $x, y, z$, supõe-se que essas coordenadas, nos problemas da mecânica, sejam funções de t. Assim, podemos considerar a mecânica como uma geometria quadridimensional e a análise mecânica como uma extensão da análise geométrica (LAGRANGE, 1797, apud ARCHIBALD, 1914) (Tradução nossa).
}

A próxima referência feita por Archibald (1914), logo após mencionar d'Alembert e Lagrange, se dirigiu ao escritor de contos de ficção científica H.G. Wells que, em 1895, escreveu "A Máquina do Tempo" ("The Time Machine”). Nesse conto, uma máquina foi inventada para viajar no tempo e a ideia de quarta dimensão temporal é abordada claramente no texto. Vale ressaltar que H.G. Wells também abordou a quarta dimensão como sendo uma dimensão espacial, em dois outros contos de ficção: "O notável caso dos olhos de Davidson" ("The Remarkable Case os Davidson's Eyes") e "A Maravilhosa Visita" ("The Wonderfud Visit"), ambos de 1895.

Archibald (1914) relaciona ao tema, ainda, matemáticos como R. Mehmke, M. Abraham, A. Sommerfeld, Wilson e Lewis, mas sem entrar em detalhes de quais contribuições foram dadas. 


\section{O Espaço-Tempo de Einstein-Minkowski}

Diferentemente do que se costuma pensar, Einstein não foi o responsável pela introdução da interpretação quadridimensional do espaço, com o tempo como a quarta dimensão. Quem introduziu a abordagem quadridimensional da Teoria da Relatividade foi Poincaré, em um trabalho de 1906, e quem a completou brilhantemente foi Hermann Minkowski, entre os anos de 1907 e 1908, no entanto, segundo Martins (2015), tanto Poincaré quanto Minkowski não estavam envolvidos com a teoria de Einstein, de 1905. Nessa época, tanto Lorentz quanto Poincaré e outros físicos já estavam buscando uma teoria da relatividade para o eletromagnetismo, devido a várias inconsistências teóricas e experimentais ligadas à eletrodinâmica dos corpos. Uma das questões principais era que as equações do eletromagnetismo não se compatibilizavam com a relatividade clássica, de Galileu, mediante a mudanças entre referenciais inerciais.

O próprio Minkowski, em 1907, já havia tomado conhecimento dos trabalhos de Einstein, no entanto, considerava tal teoria como uma generalização dos trabalhos de Lorentz, devido ao fato de que quase toda a base da teoria já havia sido desenvolvida (MILLER, 1998).

Foi Minkowski quem arquitetou os diagramas espaço-tempo para a representação das linhas de mundo, forneceu um novo formalismo para a cinemática e apresentou a forma de quadrivetores para as grandezas momentum e energia, um formalismo matemático e teórico muito mais sofisticado que os apresentados por Einstein (GALISON, 1979).

Ao que tudo indica, a ideia de tempo como uma quarta dimensão começou realmente a ganhar força na ciência a partir dos trabalhos de Poincaré, que buscou estabelecer as bases de uma teoria da relatividade para os fenômenos eletromagnéticos. Poincaré tomou como referência a teoria dinâmica do elétron, de Lorentz, e desenvolveu suas ideias sobre uma relatividade das leis físicas relacionadas ao eletromagnetismo (MARTINS, 2015).

Com os resultados negativos dos experimentos que buscavam detectar o movimento da Terra através do éter, principalmente os interferômetros de Michaelson e Morley, de 1881 e 1887, diversas especulações para justificar este resultado foram apresentadas por eminentes pesquisadores. A proposta que conduziu a resultados mais importantes foi a de FitzGerald (1851-1901), em 1889, e Hendrik Lorentz (1853-1928), em 1892, da contração longitudinal do braço do interferômetro em movimento no éter.

\section{Lorentz e Poincaré}

Em 1895, Lorentz propôs sua primeira teoria do eletromagnetismo para sistemas em movimento, partindo das equações de Maxwell, supondo a contração dos corpos que se movem ao longo do éter e considerando que as equações de Maxwell deveriam ser válidas em quaisquer referenciais inerciais. Para dar conta disso, ele propôs um grupo de equações de transformação de coordenadas para $\mathrm{x}, \mathrm{y}$, e $\mathrm{z}$, não muito diferentes das já conhecidas transformações de Galileu. Mas, ele foi forçado a introduzir uma equação de transformação adicional, para o tempo, para ajustar o eletromagnetismo a diferentes referenciais. Lorentz 
considerou tal transformação apenas como um artifício matemático, sem atribuir significado físico a este fato, e chamou a relação de "tempo local" (MARTINS, 2015).

Em alguns trabalhos posteriores, ele mesmo fez diversos ajustes em suas equações e aperfeiçoou sua teoria, entretanto, foi o matemático Henri Poincaré (1854-1912) um dos que mais contribuiu com a teoria dinâmica do eletromagnetismo de Lorentz. Em 1899, Poincaré apresentou a sua "lei da relatividade", que se tratava da proposta de que somente os movimentos relativos entre corpos materiais poderiam produzir efeitos físicos. Esta ideia já havia sido mencionada, anteriormente, por Joseph Larmor (1857-1942), mas sem maior aprofundamento (MARTINS, 2015). Em 1902, Poincaré publicou o livro "Ciência e Hipótese", onde renomeou sua lei, passando para "princípio de relatividade". Nesse trabalho, ele faz uma extrapolação dos resultados experimentais negativos obtidos durante o século XIX, conduzindo a seu princípio de relatividade, aperfeiçoa vários pontos da teoria e batiza as "Transformações de Lorentz" com este nome (MARTINS, 2015).

Em 1905, Poincaré mostra que as transformações de Lorentz implicavam em uma quebra de sincronização dos relógios em diferentes referenciais e mostra que as Transformações de Lorentz conduziam à ideia de uma dilatação do tempo, discutindo também suas implicações físicas. Por fim, em 1906, Poincaré publicou um trabalho corrigindo pequenos problemas da teoria e mostrando que as transformações de Lorentz podiam ser aplicadas entre dois referenciais inerciais em movimento no éter, assim, ele conclui que não era necessário fazer referência ao éter (MARTINS, 2015).

É então que, no mesmo trabalho de 1906, Poincaré introduziu a noção de que o tempo pode ser manipulado como uma quarta dimensão, além de ressaltar a existência de invariantes relativísticos, como o intervalo espaço-temporal que, em notação moderna, se apresenta como $d s^{2}=d x^{2}+d y^{2}+d z^{2}-c^{2} d t^{2}$ (MARTINS, 2015).

Poincaré observou que uma transformação de Lorentz é uma rotação em um espaço vetorial quadridimensional com as coordenadas $x, y, z$ e $t \sqrt{-1}$. Ele usou esse conhecimento para formar quádruplos equivalentes aos modernos quatro vetores de raio, velocidade, força e densidade de força, para aplicação em uma lei da gravitação invariante de Lorentz. Notavelmente, os detalhes de sua derivação mostram que ele não introduziu seus quádruplos como quadrivetores direcionados, mas como simples quantidades invariantes de Lorentz. Em uma palavra, quando Poincaré introduziu seu espaço vetorial quadridimensional, ele não estava, em princípio, pensando em termos do quadrivetor moderno (SCOTT, 2010, p. 3) (Tradução nossa).

Segundo Scott (2010), Poincaré reconhecia a possibilidade de uma Física nãonewtoniana, uma vez que era possível derivar uma geometria hiperbólica da inserção do tempo como dimensão adicional ao espaço. Entretanto, ele considerava empiricamente improvável a comprovação de que existiria outra geometria do espaço, que não a euclidiana, assim, continuou defendendo esta última como a geometria mais conveniente para a Física. 


\section{A contribuição de Minkowski}

Diferentemente do ponto de vista de Poincaré, que não aceitou a natureza nãoeuclidiana do espaço, Minkowski vislumbrou que a dimensão adicional ict de Poincaré conduzia a conclusão de que "[...] o mundo no espaço e no tempo, em certo sentido, é uma variedade quadridimensional não-euclidiana” (MINKOWSKI, 2012, p. 53).

Segundo Miller (1998), Minkowski havia ficado bastante impressionado com o trabalho de Poincaré, principalmente com a descoberta das propriedades do grupo de transformações de Lorentz e com a quantidade $\left(d s^{2}=d x^{2}+d y^{2}+d z^{2}-c^{2} d t^{2}\right)$, que representa um invariante de Lorentz. Foi então que, dando continuidade às pesquisas de Poincaré, ele interpretou de forma geométrica as transformações de Lorentz, agregando à relatividade do tempo de Einstein aos invariantes em um espaço vetorial quadridimensional (MILLER, 1998).

As suas ideias principais foram apresentadas pela primeira vez em dois seminários: "Espaço e Tempo" ("Raum und Zeit”), apresentada em 1908 e publicada em 1909, e "O Princípio da Relatividade" (“Das Relativitätsprinzip”), apresentado em 1907 e publicado por Arnold Sommerfeld (1868-1951), em 1915, seis anos após a morte prematura de Minkowski (GALISON, 1979). Foi na palestra de 1907 que ele expôs pela primeira vez sua representação geométrica apresentada na Fig. 1, a seguir.

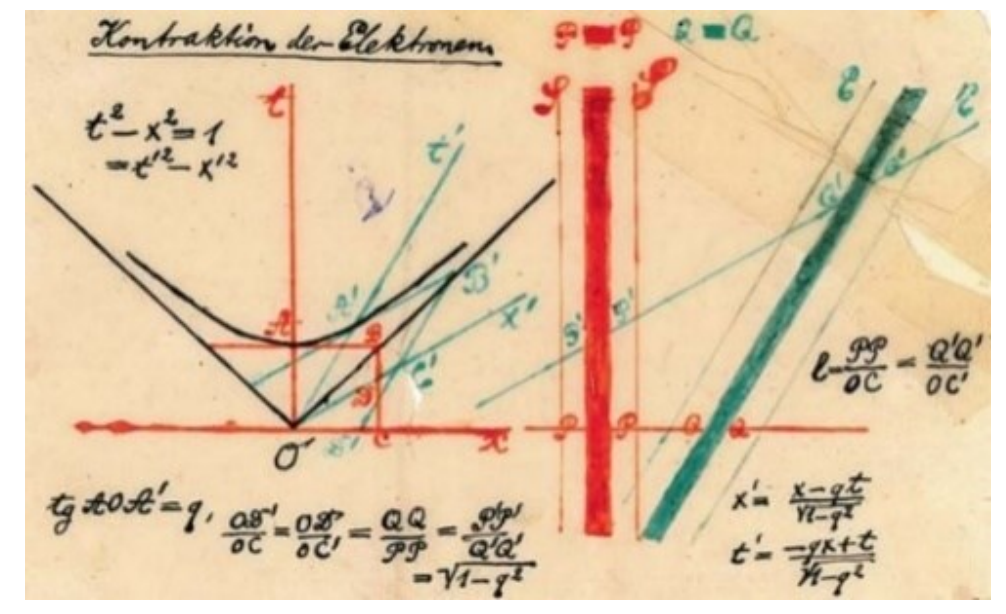

Fig. 1 - Fotocópia do slide utilizado por Minkowski em 1909.

Fonte: (MINKOWSKI, 2012, p. 32).

Segundo Miller (1998), Minkowski preparou uma estrutura que se fundamentou em Lorentz e Poincaré, juntamente com as contribuições de Einstein, para a imagem do mundo em uma estrutura quadridimensional do espaço-tempo. Porém, em seu ponto de vista, essa estrutura matemática passou a significar bem mais que uma reformulação da relatividade, um formalismo matemático eficiente, a geometria do espaço-tempo acabou adquirindo realidade física (GALISON, 1979). Em seu mundo quadridimensional, o éter de Lorentz foi 
"desmaterializado" e substituído por pontos do espaço-tempo relativístico. Nessa nova concepção de Minkowski, os únicos elementos absolutos são: a velocidade da luz (c) e os intervalos espaço-temporais $\left(d s^{2}=d x^{2}+d y^{2}+d z^{2}-c^{2} d t^{2}\right)$ (MILLER, 1997).

A própria proposta da contração de Lorentz se mostrou como uma consequência do deslocamento espaço-temporal. Na proposta original de Lorentz, da contração dos comprimentos de um dos braços do interferômetro, tal contração se devia as forças geradas sobre a estrutura do braço que viajava longitudinalmente à direção do seu movimento através do éter. Minkowski argumenta sobre isso da seguinte forma: "Esta hipótese soa extremamente fantasiosa, pois a contração não deve ser pensada como uma consequência das resistências no éter, mas simplesmente como um presente superior, como uma circunstância que acompanha o fato do movimento" (MINKOWSKI, 2012, p. 42).

Como mencionado, Minkowski avançou de sua teoria geométrica da relatividade para a extrapolação de uma concepção mais ampla e filosófica do mundo.

O sucesso de Minkowski em traduzir as leis da Física para o espaço-tempo o levou a acreditar que a nova formulação da Física exigia também uma revisão de nossas visões metafísicas. Minkowski dotou o espaço-tempo abstrato da realidade previamente concedida no espaço tridimensional e chamou o resultado "A Teoria do Mundo Absoluto” (GALISON, 1979, p. 112) (Tradução nossa).

Segundo Galison (1979), seu ponto de vista metafísico da teoria do espaço-tempo, a “Teoria do Mundo Absoluto", envolve dois conceitos físicos muito importantes, a covariância e a invariância ${ }^{8}$. A invariância está relacionada à propriedade de grandezas escalares que se mantém as mesmas em diferentes sistemas, como ocorre com a velocidade da luz ou a quantidade $\left(d s^{2}\right)$, os intervalos espaço-temporais, por exemplo. Já a covariância está relacionada a manutenção da forma das equações físicas ao serem transformadas de um referencial para outro. Ou seja, a forma de uma equação covariante permanece a mesma para quaisquer sistemas inerciais de referência.

Diversos avanços foram realizados após este trabalho de Minkowski. Por exemplo, o desenvolvimento do formalismo tensorial para o eletromagnetismo, realizados por Minkowski (1908), Sommerfeld (1910) e Abrahan (1910). Outro importante avanço foi o desenvolvimento da dinâmica relativística dos meios contínuos (fluidos e sólidos), apresentada em 1911 por Max Theodor Felix von Laue (1879-1960). Nesse trabalho, Laue se baseou no formalismo tensorial da eletrodinâmica relativística de Minkowski, Sommerfeld e Abrahan (MARTINS, 2015).

A partir de 1912, o próprio Einstein se apoiou no trabalho de Minkowski para buscar uma generalização da Teoria da Relatividade Restrita. No entanto, só em 1916 ele finalizou

\footnotetext{
${ }^{8}$ Minkowski usa a palavra "Invarianz" para se referir tanto à covariância quanto à invariância, o que pode gerar alguma confusão. Utilizaremos aqui terminologia moderna, a mesma usada por Galison (1979), evitando assim ambiguidades.
} 
suas pesquisas e conseguiu, assim, dar sequência ao seu trabalho de relatividade, chegando à Teoria da Relatividade Geral (MILLER, 1997).

A generalização da teoria da relatividade foi facilitada através da forma que Minkowski havia dado à teoria da relatividade especial. Ele foi o primeiro matemático a perceber claramente a equivalência formal das coordenadas de espaço e tempo; isso tornou possivel a construção da teoria [geral] (EINSTEIN, 1916, apud MILLER, 1998, p. 228) (Tradução nossa).

Como mencionado pelo próprio Einstein, na citação anterior, o trabalho de Minkowski foi fundamental para o desenvolvimento da Teoria da Relatividade Geral. Devido a importância do formalismo tensorial para o estudo de sistemas físicos contínuos, Einstein estabeleceu uma importante relação entre as propriedades do espaço-tempo e o tensor de momentum-energia-tensão, de Theodor F. von Laue.

Entretanto, retomando nosso tema principal, o entendimento da quarta dimensão como sendo o tempo não era a única existente ao final do século XIX e início do século XX. Nem mesmo era o mais popular, pois até a popularização dos trabalhos de Einstein, foi a interpretação espacial que alcançou o grande público.

\section{A Filosofia do Hiperespaço e seus Idealizadores}

Voltando um pouco, até o fim do século XIX, vemos que o desenvolvimento das geometrias não-euclidianas promoveu um grande impulso nas discussões sobre a curvatura do espaço, já as geometrias n-dimensionais nutriram a ideia da existência de dimensões mais elevadas, tanto para matemáticos como para pensadores populares. Esta última ideia rapidamente assumiu vida própria, tornando-se mais popular do que a noção de espaço curvo das geometrias não-euclidianas. De acordo com Sommerville (1911), essa fascinação pelas dimensões superiores surgiu pela primeira vez na Inglaterra, durante a década de 1870. Mesmo que, formalmente, representassem áreas distintas, com origens também distintas, a "quarta dimensão" se tornou, popularmente, um "codinome" para a geometria n-dimensional. Esta confusão esteve presente em muitos textos sobre o assunto, juntamente com uma variedade de conotações adicionadas ao significado geométrico da "quarta dimensão", de modo que, em 1900, o termo quarta dimensão tinha implicações filosóficas, místicas e pseudocientíficas.

Um bom exemplo é o do físico e astrônomo J.C.F. Zöllner (1834-1882), da cidade alemã de Leipzig, que defendeu que os fenômenos mediúnicos tinham conexão com a existência da quarta dimensão. Ele argumentava que a existência real do espaço quadridimensional só pode ser decidida por experiência, ou seja, pela observação dos fatos e, para ele, os fenômenos mediúnicos poderiam gerar tais provas empíricas. Tais relações entre ciência e ocultismo ocorreram mais vezes durante o século XIX. Outros exemplos deste envolvimento de cientistas com estudos espiritualistas são os do astrônomo Camille 
Flammarion (1842-1925), que estudou tais fenômenos de forma geral, do Físico-químico William Crookes (1832-1919), que estudou os fenômenos de materialização de espíritos. O próprio Michael Faraday (1791-1867) também se envolveu com o tema, estudando os fenômenos chamados de mesas girantes (FERREIRA, 2008).

Os escritores envolvidos com a visão mais filosófica da quarta dimensão acreditavam firmemente na realidade de uma quarta dimensão do espaço, mas se colocavam contrários à necessidade ou exigência de provas empíricas de sua existência. Eles assumiram uma postura fortemente antipositivista e antimaterialista. Em reação a esses pontos de vista e aos "males" que causavam, eles defendiam que o homem deveria desenvolver sua intuição e ampliar seu "sentido de espacialidade", a fim de "perceber" a quarta dimensão do mundo, a verdadeira realidade (HENDERSON, 2013).

A Filosofia do Hiperespaço também assumiu uma posição idealista, com seus escritores recorrendo frequentemente ao noumenon, a "coisa em si", de Kant, e mesmo ao mundo das ideias de Platão, na figura do mito da caverna. Com o passar do tempo, os novos escritores da Filosofia do Hiperespaço associaram a quarta dimensão a temas mais místicos como o espiritualismo, se aproximando, apenas em parte, dos trabalhos de Zöllner e, mais tarde, com os elementos do ocultismo e da Teosofia. Uma possível conexão entre a quarta dimensão e o mundo "psíquico" (psicológico) da mente, em oposição ao "mundo físico", também foi tema de discussão entre estes filósofos.

A quarta dimensão presente nos textos de Filosofia do Hiperespaço, segundo Henderson (2013), representava uma realidade, era uma dimensão real e não uma mera especulação matemática. Essa dimensão não era o próprio tempo, como viria a ser com a teoria do espaço-tempo de Einstein-Minkowski, mas sim uma dimensão extra do espaço, suprassensível, da qual nosso mundo tridimensional poderia ser apenas uma seção ou limite. Em consequência deste entendimento, o próprio ser humano não seria simplesmente um ser tridimensional, mas um ser que vive em quatro dimensões.

Para os filósofos do Hiperespaço, o tempo seria um outro elemento, não muito bem definido, mas que está intimamente ligado a esta dimensão extra. Na Filosofia do Hiperespaço, o tempo era entendido como a forma pela qual nós, seres que vivem em três dimensões, percebemos os efeitos do movimento em uma quarta dimensão, perpendicular ao nosso mundo tridimensional. Ou seja, o tempo seria um resultado da inter-relação de uma quarta dimensão do espaço com as demais três dimensões que conhecemos.

\section{Charles Howard Hinton}

O matemático inglês Charles Howard Hinton (1853-1907), considerado o primeiro filósofo do Hiperespaço, enfatizou o papel crucial do tempo em seu sistema filosófico argumentando, de forma figurada, com o auxílio da ideia de cubos tridimensionais e hipercubos quadridimensionais em movimento através de um mundo tridimensional. 
O cubo, se se movesse transversalmente ao nosso espaço, aparece como um cubo que tem duração. Um cubo de matéria tridimensional, uma vez que se estende a nenhuma distância na quarta dimensão, instantaneamente desapareceria, se sujeito a um movimento transversal ao nosso espaço. Ele desapareceria e sumiria, sem ser possivel apontar qualquer direção na qual ele se moveu. Todas as tentativas de visualizar uma quarta dimensão são fúteis. Deve estar conectado com uma experiência de tempo no espaço de três dimensões (HINTON, 1912, p. 207) (Tradução nossa).

O tempo nunca foi considerado por ele como a quarta dimensão, mas sim como um outro elemento a ser considerado (HENDERSON, 2013). A própria ideia de movimento também é analisada, por ele, em termos da quarta dimensão. A Fig. 2 representa uma alegoria onde Hinton imagina, do ponto de vista bidimensional, o movimento de uma espiral tridimensional que passa perpendicularmente por uma superfície plana. À medida que a espiral passa por esse plano bidimensional, o local de contato da espiral com o plano parecerá um "ponto" em movimento circular ao longo do tempo. Se extrapolarmos esta ideia para um mundo tridimensional, transpassado por uma espiral quadridimensional, teremos uma noção de como nossa percepção de movimento e de passagem do tempo podem ser representações tridimensionais dos fenômenos que ocorrem em quatro dimensões.

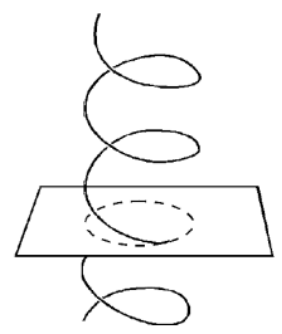

Fig. 2 - Espiral se movendo perpendicularmente a um plano.

Fonte: (HINTON, 1912, p. 25)

Ele completa sua compreensão do movimento e do tempo da seguinte forma;

Passando para quatro dimensões e nosso espaço, podemos conceber que todas as coisas e movimentos em nosso mundo são a leitura de uma realidade permanente por um espaço de consciência. Cada átomo a cada momento não é o que era, mas uma nova parte dessa linha infinita que é em si. E todo esse sistema revelado sucessivamente no tempo, que é apenas a sucessão da consciência, separado como é em partes, em sua totalidade é uma vasta unidade (HINTON, 1912, p. 26) (Tradução nossa).

Essas ideias tinham suas raízes nas geometrias não-euclidianas e n-dimensionais, mas foram as interpretações filosóficas e místicas que atraíram a atenção do público em geral, na virada do século XX. 
Hinton começou a escrever sobre o tema em 1880, no entanto, sua filosofia foi mais completamente apresentada em "Uma Nova Era do Pensamento" ("A New Era of Thought"), de 1888, e "A Quarta Dimensão" ("The Fourth Dimension"), de 1904. Além desses livros, Hinton produziu diversos artigos e textos sobre o tema: como romances, contos científicos, pequenos artigos sobre a filosofia da quarta dimensão e trabalhos mais matemáticos sobre o tema.

Apesar da sua formação em matemática e física, em Oxford, de escrever trabalhos matemáticos e lecionar em Princeton e na Universidade de Minnesota, logo após chegar nos EUA, foram seus escritos filosóficos sobre a quarta dimensão que o tornaram conhecido. Mesmo que este reconhecimento só tenha vindo posteriormente à sua morte em 1907.

Hinton propôs um método para habituar o olhar e o pensar dos homens em quatro dimensões que se baseava na complexa análise de cubos multicoloridos, Fig. 3, que ele chamou de "tesserato". A análise destes cubos, em que cada seção e cada cor representava uma ideia específica, ajudaria a ampliar o "senso espacial" do homem. A base para tal método estava na concepção de que a interpretação de Kant do espaço como a estrutura a priori, necessária para todas as percepções, tinha sido mal interpretada por seus comentadores posteriores, e sugere que nossa própria dependência do espaço tem um aspecto favorável. Segundo ele, se é através da intuição espacial que apreendemos o mundo, seria possível trabalhar sobre esse sentido espacial e desenvolvê-lo, a fim de intuir novos espaços (HENDERSON, 2013).

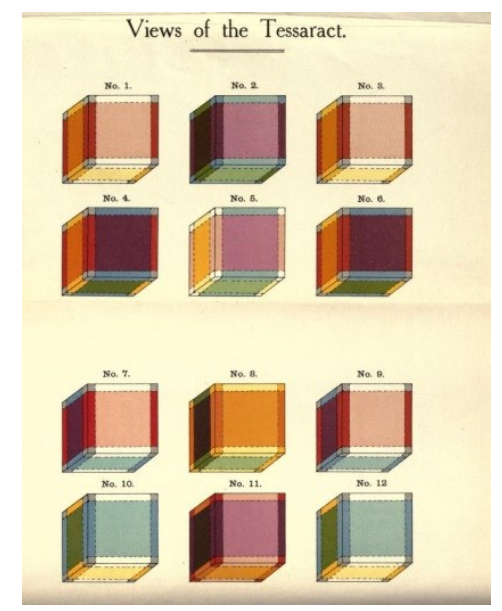

Fig. 3 - Cubos representando a quarta dimensão.

Fonte: (HINTON, 1912, p. frontispício).

Hinton acreditava que seu sistema poderia revolucionar o modo de visão da sociedade, não só filosóficas ou espaciais, mas também como o homem se relaciona com o mundo em que vive. Ele acreditava que o modo de concepção do espaço de quatro dimensões e os meios de ensiná-lo estavam estruturados. 
Eu apresentarei um sistema completo de pensamento quadridimensional: mecânica, ciência e arte. A condição necessária é que a mente adquira o poder de usar o espaço de quatro dimensões como faz agora tridimensionalmente. E há uma condição que não é menos importante. Nós nunca podemos ver, por exemplo, imagens quadridimensionais com nossos olhos corporais, mas podemos com nossos olhos mentais e interiores. A condição é que devemos adquirir o poder de carregar mentalmente um grande número de detalhes (HINTON, 1888, p. 86) (Tradução nossa).

Ele acreditava na ideia de que uma pequena extensão no espaço de quatro dimensões poderia ser a conexão entre nosso mundo e a quarta dimensão e, assim, poderia ser útil para os cientistas que estudam as partículas de matéria. Ele chega a discutir a teoria de átomos como vórtices do éter, de Lord Kelvin, e outras noções incomuns que fascinaram muitos amantes da ciência no final do século XIX. Hinton sugere que as partículas de éter em movimento nas quatro dimensões produziriam vórtices com características semelhantes às correntes elétricas. Assim, na visão de Hinton, a eletricidade poderia muito bem ser um fenômeno quadridimensional (HENDERSON, 2013).

De acordo com Henderson (2013), o sistema completo do pensamento quadridimensional de Hinton (mecânica, ciência e arte) nunca foi terminado por ele. A sua maior contribuição foi a interpretação filosófica da quarta dimensão e sua defesa de uma ciência livre das restrições do positivismo tradicional. Suas ideias filosóficas e científicas se tornaram recorrentes nos trabalhos posteriores sobre a quarta dimensão (HENDERSON, 2013).

Apenas como curiosidade, uma dessas coincidências da vida, entre os anos de $1902 \mathrm{e}$ 1907, na época em que Albert Einstein trabalhava no escritório de patentes da Suíça, Charles Howard Hinton era empregado no escritório de patentes dos Estados Unidos, em Washington, DC (HENDERSON, 2013).

\section{Claude Fayette Bragdon}

Outro grande filósofo do Hiperespaço foi o arquiteto americano, designer de teatro e editor da "Manas Press", em Rochester, de 1909 a 1921, Claude Fayette Bragdon (18661946). Filho de um teosofista, ele ajudou a fundar a Loja Genesee da Sociedade Teosófica em Rochester e sempre manteve uma crença fervorosa na filosofia esotérica e nos fenômenos ocultos. Segundo Henderson (2013), Bragdon foi apresentado ao conceito da quarta dimensão, em 1907, por um amigo e pelo próprio filósofo do Hiperespaço Howard Hinton. A partir daí, Bragdon dedicou-se a esta ideia e produziu quatro livros e diversos artigos a respeito da quarta dimensão.

Embora Bragdon tenha se empenhado para entender as leis matemáticas do espaço quadridimensional, trabalhando em colaboração com o matemático Philip Henry Wynne (1868-1919), entre 1911 e 1912, era o significado filosófico da quarta dimensão que mais 
importava para ele, da mesma forma que havia sido anteriormente para Hinton (HENDERSON, 2013).

A Filosofia do Hiperespaço de Bragdon, assim como a de Hinton, confere ao tempo um papel limitado na conceituação da quarta dimensão. Para ele, o tempo representa o primeiro meio pelo qual podemos sentir dimensões mais elevadas, no entanto, assim como Hinton, ele não atribui ao tempo a identidade da quarta dimensão, mas um elemento fundamental na compreensão desta dimensão superior.

O primeiro texto mais extenso de Bragdon sobre a quarta dimensão, foi um panfleto denominado de "O Homem Quadrado: Uma Parábola do Espaço Superior" ("Man the Square: A Higher Space Parabole"), e se trata de uma parábola religiosa que emprega a analogia de um mundo de duas dimensões para tratar do amor e da harmonia entre os homens (HENDERSON, 2013). Este panfleto foi reimpresso, como apêndice, em seu trabalho mais importante, "Uma cartilha para o Espaço Superior (A Quarta Dimensão)" ["A Primer of High Space (The Fourth Dimension)"], de 1913, onde estão apresentadas suas principais ideias. No "Primer", Bragdos desenha trinta placas que ilustram quase todas as ideias populares de sua época sobre a quarta dimensão. Segundo Henderson (2013), Bragdon foi o primeiro autor a, de fato, ilustrar a analogia do mundo bidimensional cortado por objetos tridimensionais, tão discutido pelos escritores que, simplesmente, descreviam tal ideia em seus textos. Além disso, ele empregou diagramas e projeções para explicar os progressivos acréscimos dimensionais explicados pela translação de uma linha para gerar um plano, de um plano para geral um cubo, e de um cubo para o hipercubo, o tesserato de Hinton (Fig. 4).

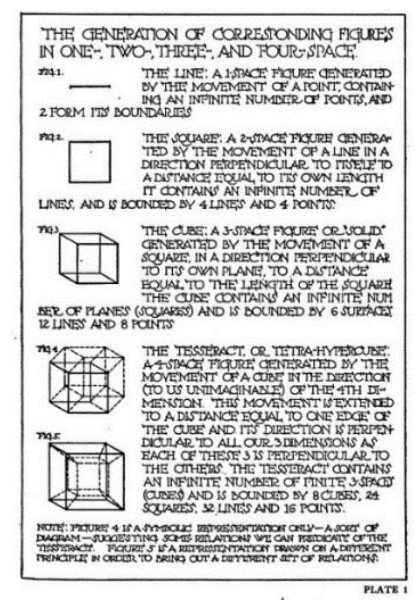

Fig. 4 - Placa 1: Representação da progressão entre as dimensões espaciais.

Fonte: (BRAGDON, 1913, p. 42).

Para Bragdon, a desarmonia deste mundo é resultado da incapacidade do homem perceber sua existência quadridimensional. Segundo ele, nos parecermos como seres individualmente diferentes devido ao fato de que nossas "projeções" nesse mundo 
tridimensional ocorrem de forma diferente para cada um. Entretanto todos somos iguais em quatro dimensões. Para ilustrar esta ideia, ele se vale da analogia de que, se fossemos todos cubos tridimensionais, atravessando uma superfície plana, um mundo em duas dimensões, em diferentes angulações, nossas imagens produzidas nesse mundo plano seriam figuras geométricas planas variadas, conforme a Fig. 5.

É por essa analogia que ele define como as nossas diferentes personalidades e características se estabelecem, mas que são apenas formas aparentes (BRAGDON, 1913).

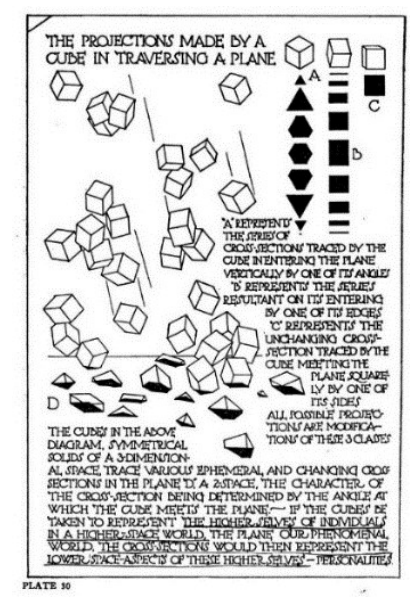

Fig. 5 - Placa 30: Ilustração de cubos tridimensionais atravessando um plano. Fonte: (BRAGDON, 1913, p. 72).

Na parábola religiosa "Man the Square: A Higher Space Parabole", onde Bragdon descreve a existência de um mundo plano em que os seres que lá residem desconhecem sua natureza mais elevada. A real existência superior desses seres é tridimensional, como cubos, mas sua existência aparente é diversificada, semelhantes às seções planas registradas na Fig. 5 .

No entanto, esta realidade tridimensional só é revelada quando um cubo "Christos" desdobra seus seis lados no plano, em forma de cruz (Fig. 6). Então, uma vez conscientes de sua verdadeira natureza tridimensional, todos os homens-cubo se apresentam como "quadrados" sobre esse mundo plano em que vivem.

Para ele, todo o processo evolutivo do ser consiste na conquista de sua consciência, dimensão por dimensão, até alcançarmos a máxima compreensão do mundo. Claramente, ele estava misturando a Filosofia do Hiperespaço com a interpretação de evolução espiritual da teosofia, em um processo de "expansão da consciência". Sua formação teosofista é bastante presente em seus escritos e, assim, ele deixa muito evidente a visão mais abertamente mística da quarta dimensão. 


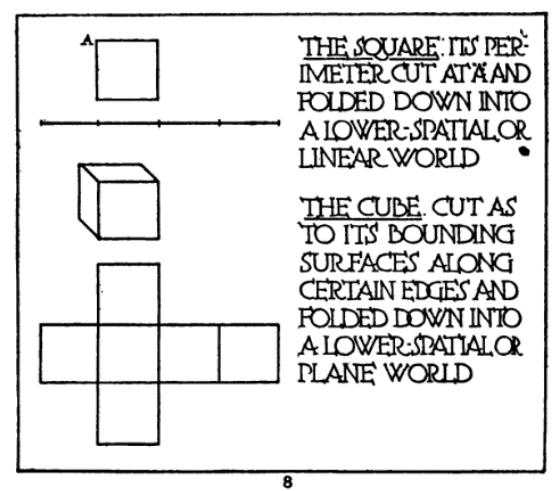

Fig. 6-Desdobramento de um cubo em um plano. Fonte: (BRAGDON, 1912, p. 27).

\begin{abstract}
A ascensão biológica e a ascensão da consciência significam, assim, uma remoção constante da fronteira entre representação e realidade, à custa da parte transcendental do mundo, e em favor da parte percebida. Agora, se esse limiar psicofisico em mutação é simplesmente a linha divisória entre os espaços inferiores e superiores, então todo o processo evolutivo consiste e a conquista, dimensão por dimensão, dos sucessivos mundos espaciais (BRAGDON, 1913, p. 14-15) (Tradução nossa).
\end{abstract}

Além disso, Bragdon viu na quarta dimensão um significado para sua arquitetura. Ele estava convencido de que um novo modo ornamental era necessário para um novo futuro, onde " $A$ arte deve se harmonizar com essa nova realidade [quadridimensional] do mundo moderno" (BRAGDON, 1915, p. 11). E ele continua dizendo:

A consciência está se movendo em direção à conquista de um novo espaço; o ornamento deve indicar esse movimento de consciência; a geometria é o campo no qual nós estabelecemos nossa reivindicação particular. Segue-se, portanto, que no solo da geometria de quatro dimensões devemos plantar nossa pá metafísica (BRAGDON, 1915, p. 11) (Tradução nossa).

Ele propôs que nosso conhecimento do espaço é incompleto e essa compreensão espacial exige que outras modificações sejam corretamente conhecidas:

Nossa ideia de espaço é parcial e, como muitas outras ideias, precisa ser modificada para acomodá-la a um conhecimento mais completo. O que pensamos como espaço é mais provavelmente apenas uma parte do espaço perceptivel. [...] Em outras palavras, talvez o que pensamos como espaço seja apenas tanto quanto o nosso limitado mecanismo sensitivo seja capaz de apreender (BRAGDON, 1913, p. 5) (Tradução nossa).

Uma ilustração que conectou a clarividência com a visão quadridimensional também foi incluída em uma de suas placas. Não há referência, nos textos, à palavra "raios X", no entanto, a figura se apropria da representação transparente de objetos sólidos muito próximo 
da imagem associada a uma radiografia (Fig. 7, placa 19). A relação entre a teosofia, a clarividência e a descoberta dos Raios X por Röntgen (1845-1923), em 1895, era muito explorada pelos teosofistas como evidência de uma existência superior, espiritual (HENDERSON, 1988).

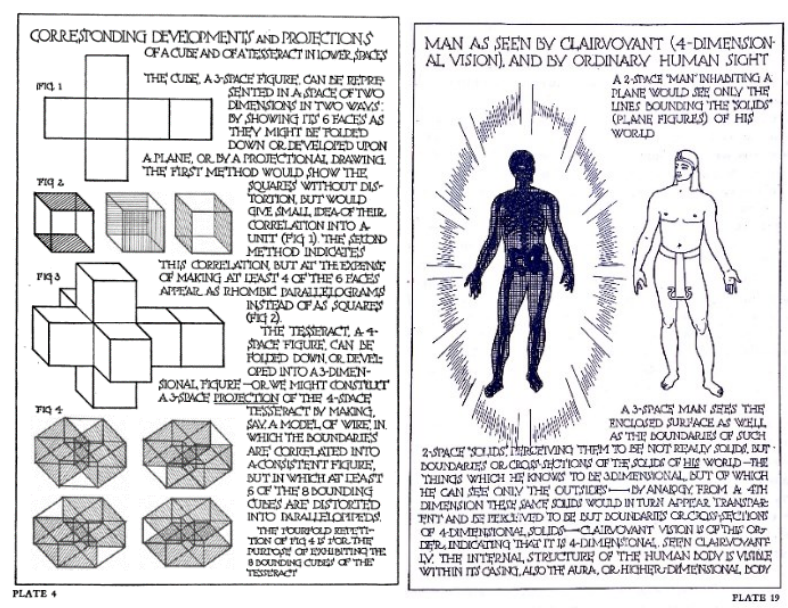

Fig. 7 - Placa 4: Dimensões representadas no plano; Placa 19: Visão clarividente. Fonte: (BRAGDON, 1913, p. 45 e 60).

Por volta de 1918, Bragdon descobriu o livro "Tertium Organum", de 1911, do escritor russo Piotr (Peter) Demianovitch Ouspensky (1878-1947). Ouspensky compartilhava da crença teosofista de Bragdon e desenvolveu suas próprias ideias em torno da quarta dimensão, direcionando este conceito para uma concepção mais mística, assim como Bragdom. Ambos foram contemporâneos, mas não se conheceram pessoalmente. Seu único contato ocorreu através dos seus textos. Suas obras são relativamente independentes, a não ser pela coincidente aproximação de serem, ambos, teosofistas e terem forte influência dos escritos de Hinton (HENDERSON, 2013).

Em 1918, Bragdon colaborou entusiasticamente da tradução, para o inglês, do Tertium Organum, originalmente em russo, publicado em 1920 pela editora Manas Press. Da mesma forma, mais tarde, Ouspensky registrou sua emoção ao ler os textos de Bragdon e perceber como eles dialogavam tão perfeitamente, mesmo sem se conhecerem (HENDERSON, 2013).

\section{Piotr (Peter) Demianovitch Ouspensky}

Ouspensky foi um matemático e filósofo russo considerado o grande sucessor de Hinton no desenvolvimento da Filosofia do Hiperespaço. De acordo com Henderson (2013), ele teve uma formação intelectual ampla, formando-se em matemática e nutrindo inclinações artísticas influenciadas pelo amor de seu pai pela música, de um avô pintor e de uma mãe com inclinações para pintura e literatura. 
Depois de se formar na Universidade de Moscou e trabalhar como jornalista, voltouse para uma coleção de textos de literatura ocultista e que, embora as considerasse "muito ingênuas", encontrou identificação com sua oposição ao "deserto árido" do positivismo. Desde então, este se torna o princípio de sua filosofia, a ideia de que a quarta dimensão é a chave dos mistérios do mundo (BURCH, 1951).

Ouspensky é considerado o verdadeiro sucessor de Hinton, no entanto, ele desenvolveu uma marca exclusiva de Filosofia do Hiperespaço. Ele aproximou o conceito de quarta dimensão da doutrina Teosofista, acrescentando elementos místicos e psicológicos que não eram claros na filosofia de Hinton. Os trabalhos de Hinton foram cruciais para o desenvolvimento de seu pensamento, com respeito a quarta dimensão. Outra fonte que parece ter influenciado foram os trabalhos de autores de contos de ficção científica, como o de HG Wells, “A Máquina do Tempo", que pode ter sido uma das maiores fontes de divulgação do tema na Rússia (HENDERSON, 2013).

Foi através da literatura da Teosofia, por volta de 1907, que sua convicção antipositivista se fortaleceu ainda mais. Os preceitos teosofistas, juntamente com seus estudos sobre a quarta dimensão, o conduziram à estruturação de suas próprias ideias sobre o assunto. Sua preocupação principal, com respeito às dimensões mais elevadas, se estruturou a partir de análises tanto geométrica, como do ponto de vista psicológico e seu primeiro livro, "A Quarta Dimensão" ("четвертое измерение"), foi publicado em 1909. Esse livro, basicamente, se trata de um relato das ideias sobre a quarta dimensão que eclodiram ao longo do século XIX.

A epistemologia de Ouspensky é apresentada sistematicamente no "Tertium Organum"9 de 1911 e se apresenta como um "terceiro cânone do pensamento" ocidental. Este, segundo ele, seria um terceiro método para se alcançar o conhecimento, na sequência do método dedutivo Aristotélico e do método indutivo, descrito por Bacon. Seria o método voltado para o místico, que sempre existiu no pensamento humano, embora tenha se afastado de nós, "modernos", e sido rotulado de irracional (BURCH, 1951).

Rejeitando a abordagem puramente geométrica, Ouspensky propõe que o problema deve ser estudado tanto do lado psicológico quanto físico. Ele segue, de certa forma, as ideias de Hinton que procurou despertar uma "consciência superior", psicológica, em seus leitores, através da educação dos sentidos para a percepção da quarta dimensão (HENDERSON, 2013).

Ele inicia o "Tertium Organum" relatando a filosofia kantiana e indicando que seu sistema de pensamento é uma evolução, uma sequência do idealismo Kantiano. Para Kant, o espaço e tempo são propriedades do intelecto, como intuições da mente humana e, em vez de rejeitarmos Kant como fizeram os matemáticos pós geometrias não-euclidianas, ele localiza a

\footnotetext{
${ }^{9}$ Disponível em: <https://archive.org/details/tertiumorganumth00ousp/page/n2>. Acesso em: 01 jul. 2019. (A primeira tradução para o inglês foi feita por Nicholas Bessaraboff e pelo próprio Claude Bragdon, que ficou maravilhado com esta literatura distante e que versava sobre as próprias ideias que ele mesmo nutria. A obra foi publicada pela Manas Press em 1920 e depois revisada por Alfred Knopf em 1922.)
} 
fonte de nossas concepções de espaço na mente e busca ampliar a consciência humana, para incluir intuições de espaços dimensionais superiores.

Ele sentiu que, de alguma forma, a quarta dimensão estava conectada com o mundo "psíquico" (psicológico) da mente, em oposição ao "mundo físico". Dando os passos seguintes ao próprio Hinton, ele dedica grande parte do "Tertium Organum" a um estudo das condições de nossa receptividade, a fim de determinar qual a natureza da consciência e provar que tal expansão da consciência é viável.

Segundo Henderson (2013), Ouspensky redefine a noção de tempo em termos de espaço. Mesmo entendendo a importância do tempo no decorrer dos fenômenos, ele jamais imaginou a quarta dimensão apenas como tempo. Para ele, a própria noção de tempo é transitória e sua relevância tenderia a retroceder à medida que nossa compreensão espacial aumentasse.

Como dedução de todos os precedentes, podemos dizer que o tempo (como é geralmente entendido) inclui em si duas ideias: a de um certo espaço desconhecido para nós (a quarta dimensão) e a de um movimento sobre esse espaço. Nosso erro constante consiste no fato de que, com o tempo, nunca vemos duas ideias, mas vemos sempre apenas uma. Normalmente, vemos no tempo a ideia de movimento, mas não podemos dizer de onde, onde, nem em que espaço. Tentativas foram feitas até agora para unir a ideia da quarta dimensão com a ideia de tempo. Mas naquelas teorias que tentaram combinar a ideia de tempo com a ideia da quarta dimensão, aparecia sempre a ideia de algum elemento espacial como existindo no tempo, e junto com ele era admitido o movimento naquele espaço. Aqueles que estavam construindo essas teorias, evidentemente, não entenderam que, deixando de fora a possibilidade de movimento, eles estavam promovendo a demanda por um novo tempo, porque o movimento não pode prosseguir fora do tempo (OUSPENSKY, 1922, p. 45) (Tradução nossa).

Segundo Ouspensky, o homem é dotado, vulgarmente de uma "consciência simples" que o conduz às noções mais básicas do ser. Iniciada sua busca por autoconhecimento ele se eleva gradualmente para a "autoconsciência" e, através de seu esforço, ele poderá alcançar níveis mais elevados de uma "consciência cósmica"

A consciência cósmica é também possivel de ser alcançada através da emoção inerente à criação - em pintores, músicos e poetas. A arte em suas mais altas manifestações é um caminho para a consciência cósmica. Mas, igualmente em todos

\footnotetext{
${ }^{10}$ O termo "consciência cósmica" usado por Ouspensky tem origem no livro "Cosmic Consciousness: A Study in the Evolution of the Human Mind", de 1901, do proeminente psiquiatra canadense Richard Maurice Bucke (1837-1902). Este termo, por sua vez, foi derivado da variação do conceito oriental de "consciência universal", originalmente presente no livro "From Adam's Peak to Elephanta: Sketches in Ceylon and India", de 1892, de Edward Carpenter. Carpenter foi um filósofo e poeta inglês que conta suas experiências espirituais após uma viajem longa pela Índia e Ceilão em 1890.
} 
os casos, o desdobramento da consciência cósmica exige uma certa cultura, uma vida correspondente (OUSPENSKY, 1922, p. 331) (Tradução nossa).

Ouspensky acreditava que aspectos da "nova Física" de Einstein e Minkowski haviam provado as limitações do positivismo e a correção de sua própria previsão de uma quadridimensionalidade, acompanhada pelo desaparecimento de nossa compreensão comum do tempo. Do campo da matemática, ele empregou a matemática dos números transfinitos ${ }^{11}$ para elaborar seu ataque ao mundo tridimensional da matéria, do positivismo (HENDERSON, 2013).

Curiosamente, embora o conceito da quarta dimensão fosse central para sua filosofia, diferentemente dos seus antecessores, Ouspensky não fez uso das próprias geometrias como prova dos erros do positivismo.

\section{Proposta didática}

A proposta didática, aqui apresentada, está em fase final de elaboração e será aplicada, conforme já mencionado, em uma turma da disciplina de Física Moderna 1, no primeiro semestre de 2020. Esta disciplina é obrigatória do curso de licenciatura em Física em questão e já vem sendo realizada por vários anos, mas sempre com uma ementa e proposta didática que podemos chamar de ortodoxa ${ }^{12}$. Os conteúdos ministrados são os de Relatividade Restrita, introdução a Relatividade Geral (discussões apenas conceituais) e introdução a Física Quântica (partindo da radiação de corpo negro até o modelo de Bohr e uma pincelada no princípio de incerteza e equação de de Broglie).

Esta disciplina conta com 20 semanas de aula, com 4 tempos de aula de $50 \mathrm{~min}$ em cada semana. Em geral, a distribuição é de dois encontros semanais. Os conteúdos são divididos da seguinte forma: as 10 primeiras semanas são usadas para as Teorias da Relatividade Restrita e Geral e as 10 últimas para a Física Quântica. Os assuntos de Relatividade Geral são aplicados apenas de forma conceitual, sem aprofundamento matemático, o que consome uma semana, no máximo. Nossa proposta se restringe à primeira parte da disciplina em questão. Assim, nossa proposta didática será aplicada ao longo das primeiras 10 semanas. Teremos 20 encontros de $1 \mathrm{~h}$ e 30 min cada. Serão, aproximadamente, $33 \mathrm{~h}$ para a realização desta proposta. Como iremos consumir as 10 primeiras semanas com a proposta didática, iremos tomar uma semana de aula que seria destinada à Física Quântica para abordar a Relatividade Geral, no entanto nossa proposta didática já estará encerrada.

\footnotetext{
${ }^{11}$ Um número transfinito é a forma rigorosa usada pela matemática para contar o número de elementos de conjuntos infinitos, desenvolvida por George Cantor (1845-1918) ao elaborar a Teoria dos Conjuntos. Segundo ele, os números transfinitos são uma extensão sistemática dos números naturais.

${ }^{12}$ O significado original do termo vem do grego "orthos" que significa "reto" e "doxa" que significa "fé", ou seja, é aquilo que está em conformidade com determinada doutrina religiosa tida como verdadeira. A palavra "ortodoxo" é muito usada ao se referir a algo rígido, tradicional, conservador, que não se adapta nem admite inovações. No presente texto, usaremos este termo com esse significado: rígido, conservador etc.
} 
Trata-se de uma abordagem interdisciplinar ${ }^{13}$ em que o pilar central será a discussão sobre as modificações da concepção de espaço e tempo da Física Clássica para a Teoria da Relatividade. Em linhas gerais, é essa a filosofia de um curso de relatividade, pois o que se faz comumente é a apresentação dos conflitos ligados a relatividade clássica e aos conceitos absolutos de tempo e espaço, depois se introduz os alunos nos conceitos e formalismos matemáticos da Teoria da Relatividade de Einstein e, por fim, se discutem as implicações desta última.

Os conteúdos necessários para a integralização da disciplina não serão esquecidos, serão abordados, mas com propósitos agregados que vão além dos conteúdos científicomatemáticos. No entanto, é óbvio que teremos que elencar os conteúdos mais importantes, reduzir a quantidade de exercícios de aplicação, que são exaustivamente repetitivos na maioria dos casos, além de realocar melhor alguns outros tópicos da disciplina.

As aulas não serão separadas em encontros com abordagem interdisciplinar e outro com aula propedêutica ${ }^{14}$, o que não faria sentido em uma proposta interdisciplinar, mas é lógico que teremos diferentes níveis de interdisciplinaridade para diferentes temas de aula. Acreditamos que um discurso interdisciplinar dos conteúdos, que uma apresentação desses conteúdos de modo que as fronteiras entre as áreas não sejam muito definidas, será muito mais viável que uma apresentação histórica, seguida de uma formalização teórico-matemática e depois uma discussão de contexto cultural.

Utilizaremos alguns artigos e textos de outros autores, que já tratam muito bem dos temas que queremos abordar em determinadas aulas, e mais os textos de autoria própria, para os temas específicos de nossa proposta. Especificamos os momentos de utilização desses textos nas Tabelas 1 e 2 .

A elaboração dos nossos próprios textos fez-se necessária devido à complexidade $\mathrm{e}$ extensão dos trabalhos específicos de História da Arte e História da Ciência que tratam do assunto. A leitura destas fontes pelos alunos seria inviável devido a diversos fatores como: a linguagem muitas vezes rebuscada e repleta de referências histórico-filosóficas que, em geral, os alunos de graduação ainda não detêm e textos muito extensos, em alguns casos o aluno teria que ler um livro inteiro para poder chegar a conclusões consistentes. Nossos textos,

\footnotetext{
${ }^{13}$ Compartilhamos do entendimento de interdisciplinaridade de Japiassu (2006), onde a necessidade de integração dos saberes conduz a inter-relações entre eles. O entendimento de interdisciplinaridade adotado nesse trabalho é o de um processo educacional pelo qual os saberes disciplinares trocam informações e se interrelacionam no interior da pesquisa, rompendo as estruturas fronteiriças de suas teorias próprias. Buscamos, com isso, mais que a convergência e a complementaridade de disciplinas, buscamos obter sínteses que extrapolem os limites de uma área individual do saber (JAPIASSU, 2006). Isso porque entendemos a Ciência como parte da Cultura, assim como Zanetic (1989), e o conhecimento humano como um processo complexo, assim como Morin (2005).

${ }^{14} \mathrm{O}$ termo tem origem do grego propaideutikós, que é "relativo à instrução", onde é possível perceber a referência da ideia de ensino. Desta forma, "propedêutico" se refere ao corpo de ensinamentos básicos de uma disciplina.
} 
então, representam a transposição didática de livros e artigos específicos destas áreas citadas e seus títulos são os seguintes:

Texto 1. Relatividade de Lorentz e Poincaré (histórico-conceitual);

Texto 2. O conceito de quarta dimensão e a Filosofia do Hiperespaço;

Texto 3. O espaço-tempo de Minkowski;

Texto 4. A quarta dimensão na literatura do final do século XIX;

Texto 5. As artes plásticas do início do século XX e a quarta dimensão.

Voltamos a dizer que os Textos 1, 2 e 3 contém as discussões apresentadas no presente trabalho, levemente estendidos. Os Textos 4 e 5 estão em fase de elaboração.

Todo o material didático será proposto aos alunos com antecedência e o cronograma será disponibilizado para que eles se organizem e saibam qual texto estudar para cada aula. A leitura dos textos deverá ser feita previamente por eles, de preferência na véspera da aula correspondente a cada assunto.

As tabelas 1 e 2, a seguir, apresentam as 10 semanas de duração do curso, divididas em dois encontros por semana. Procuramos propor apenas um texto por semana para leitura, com exceção apenas na $8^{\text {a }}$ semana. A coluna denominada Temas, são os temas de aula para cada dia. Já a coluna descrita como conteúdo "ortodoxo" dizem respeito ao conteúdo estritamente de física a ser abordado durante o desenrolar do tema.

Tabela 1 - Primeira etapa do curso.

\begin{tabular}{|l|l|l|l|}
\hline N & Temas & Conteúdo “ortodoxo" & Textos \\
\hline \multirow{3}{*}{1} & O espaço e o tempo clássicos & $\begin{array}{l}\text { Espaço e tempo homogêneos, isotrópicos } \\
\text { e absolutos; } \\
\text { Espaço euclidiano. }\end{array}$ & (REIS e REIS, 2016) \\
\cline { 2 - 5 } & Relatividade Clássica & $\begin{array}{l}\text { Relatividade clássica e transformações de } \\
\text { Galileu. }\end{array}$ & (REIS e REIS, 2016) \\
\hline \multirow{3}{*}{2} & $\begin{array}{l}\text { Eletromagnetismo x mecânica, } \\
\text { ondas eletromagnéticas e o } \\
\text { éter }\end{array}$ & $\begin{array}{l}\text { Conflito entre o magnetismo e a } \\
\text { Relatividade clássica. }\end{array}$ & (MARTINS, 2012) \\
\cline { 2 - 5 } & $\begin{array}{l}\text { Tentativas de detecção do éter. } \\
\text { A teoria da relatividade de } \\
\text { Lorentz e Poincaré. }\end{array}$ & $\begin{array}{l}\text { Os tranterferômetro de Michaelson e ermações de Lorentz, contração } \\
\text { dos comprimentos, dilatação do tempo 15. }\end{array}$ & Texto 1 \\
\cline { 2 - 5 } & $\begin{array}{l}\text { Diferenças entre a TRR de } \\
\text { Einstein e a de L. e P. }\end{array}$ & $\begin{array}{l}\text { Postulados, contração dos comprimentos, } \\
\text { dilatação do tempo, por Einstein. }\end{array}$ & Texto 1 \\
\hline
\end{tabular}

\footnotetext{
${ }^{15}$ Este assunto foi deslocado para antes da apresentação da teoria de Einstein, uma vez que queremos destacar que estas ideias precederam Einstein. Lorentz já havia desenvolvido suas equações e apresentado a hipótese da contração dos comprimentos e dilatação do tempo (que ele chamou de tempo local). Já Poincaré havia desenvolvido uma teoria da relatividade, partindo das ideias de Lorentz. No entanto estas ideias tinham pontos de vista teórico-epistemológicos diferentes da teoria de Einstein. Trataremos, aqui, da dilatação dos tempos e contração dos comprimento através das transformações de Lorentz.
} 


\begin{tabular}{|c|c|c|c|}
\hline \multirow{2}{*}{4} & $\begin{array}{l}\text { O contexto do trabalho de } \\
\text { Einstein }\end{array}$ & Continuação & (GALISON, 2005) \\
\hline & Exercícios & Exercícios & - \\
\hline & A relação massa energia & Dinâmica relativística & $\begin{array}{l}\text { (BARCELLOS } \\
\text { ZANETIC, 2007) }\end{array}$ \\
\hline & Continuação & Continuação & $\begin{array}{l}\text { (BARCELLOS } \\
\text { ZANETIC, 2007) }\end{array}$ \\
\hline
\end{tabular}

Fonte: Dos próprios autores.

Separamos em duas tabelas apenas para melhor adequar o tamanho da tabela às regras de publicação, mas podemos notar que a segunda tabela trata, mais especificamente, das discussões histórico, científico e culturais da nossa proposta.

Estes textos não substituirão os livros didáticos comumente usados, mas servirão de suporte às discussões contextuais e históricas. Os conteúdos formais, comumente discutidos nessa disciplina, serão abordados dentro das discussões histórico-culturais e, conforme já mencionado, não haverá separação entre encontros com aulas contextuais e encontros propedêuticos, mas é obvio que teremos alguns encontros com abordagens mais matematizadas e outros menos.

Em determinados momentos não detalharemos o formalismo matemático utilizado na época em que as teorias foram desenvolvidas, para não causar confusão na mente dos alunos. Iremos trabalhar as discussões histórico-conceituais e apresentar tal formalismo, mas apenas de forma ilustrativa. Utilizaremos os formalismos matemáticos modernos, mas com os devidos esclarecimentos para não incorrermos em um anacronismo ingênuo ou deliberado.

Tabela 2 - Segunda parte do curso, finalizando com as avaliações.

\begin{tabular}{|c|c|c|c|}
\hline $\mathrm{N}$ & Tema & Conteúdo "ortodoxo" & Textos \\
\hline \multirow[b]{2}{*}{6} & Aula de exercícios & Aula de exercícios & $-\ldots$ \\
\hline & $\begin{array}{l}\text { A quarta dimensão, uma cultura } \\
\text { de época. }\end{array}$ & $\begin{array}{l}\text { Espaço-tempo de Minkowski, } \\
\text { quadrivetor, invariância e covariância. }\end{array}$ & Texto 2 \\
\hline \multirow{2}{*}{7} & Continuação & Continuação & Texto 3 \\
\hline & Aula de exercícios & Aula de exercícios & $-\ldots$ \\
\hline \multirow[b]{2}{*}{8} & $\begin{array}{l}\text { A quarta dimensão na literatura e } \\
\text { nas artes. }\end{array}$ & & Textos 4 e 5 \\
\hline & $\begin{array}{l}\text { Consequências culturais da } \\
\text { popularização da Teoria da } \\
\text { Relatividade de Einstein }\end{array}$ & $\begin{array}{l}\text { Adições relativísticas de velocidade, } \\
\text { Efeito Doppler. }\end{array}$ & Textos 4 e 5 \\
\hline \multirow{2}{*}{9} & Aula de exercícios & Aula de exercícios & $-\ldots$ \\
\hline & Aula de exercícios & Aula de exercícios & $\ldots$ \\
\hline
\end{tabular}




\begin{tabular}{|l|l|l|l|}
\hline \multirow{2}{*}{10} & Avaliações (1) & Avaliações (1) & - . . - \\
\cline { 2 - 4 } & Avaliações (2) & Avaliações (2) & - . . - \\
\hline
\end{tabular}

Fonte: Dos próprios autores.

Na semana de avaliações, iremos realizar dois tipos de avaliação:

1 - Avaliação formal escrita - um bloco de questões relativas ao conteúdo ortodoxo, com questões conceituais e algumas questões que exigirão formalismo matemático.

2 - Apresentação de um resumo dos textos lidos até o momento, mas em formato de apresentação. Nesta avaliação, os alunos irão preparar uma apresentação que resuma o que foi discutido até aquele momento. Eles poderão se apresentar em grupos, terão liberdade de separar qual parte cada aluno apresentará e qual o formato da apresentação: vídeo, projeção em "slides", performance etc. O que será avaliado é a interação dos mesmos com as discussões, a criatividade, e o domínio do conhecimento discutido. Não é comum este curso contar com número elevado de alunos, dificilmente superando 10 alunos, o que facilita tal avaliação.

Como as aulas são divididas em dois dias, no primeiro dia será feita a avaliação 1 e no outro dia a avaliação 2 . Os alunos serão orientados, desde as primeiras aulas, a registrarem nos textos as partes que considerarem mais significativas, a fazerem anotações nas discussões, que parecerem relevantes, e irem registrando o que pode ser importante de ser apresentado no dia da apresentação de avaliação.

Não temos, até o momento, a intenção de aplicar questionários para avaliações prévia e posterior ou outro tipo de pesquisa ligada a esta proposta. Mas estamos estudando a viabilidade de tal aplicação. Entendemos que esta proposta, até o momento, já exigirá um cuidado e atenção elevados para que seja efetiva. Agregar uma pesquisa poderia desviar a atenção que queremos dar ao processo como um todo.

Nossa proposta é que o curso seja realmente interdisciplinar, o que nos parece bastante desafiador por se tratar de uma disciplina obrigatória de Física, de um curso de graduação. Talvez, após a realização desta proposta, possamos concluir que seja necessário e viável agregar alguma pesquisa a uma segunda aplicação da mesma proposta.

A expectativa para tal empreendimento é de que, além de promovermos maior interesse e participação dos alunos nas aulas, possamos dar o exemplo de que é possível e totalmente viável a abordagem interdisciplinar para o ensino de Física. Como se trata de um curso de formação de professores, nos parece muito efetivo que a vivência de exemplos de práticas, diferentes das ortodoxas, possa encorajar estes alunos a executá-las em suas futuras práticas pedagógicas.

Outra expectativa é que possamos contribuir para uma formação mais consciente sobre a construção do conhecimento científico e do papel da ciência na sociedade. Esperamos, 
também, que consigamos mostrar para os alunos a inconsistência da ideia de uma ciência linearmente construída, neutra, isolada dos demais âmbitos culturais e mesmo ahistórica.

\section{Conclusão}

Como foi apresentado ao longo deste trabalho, o entendimento de que o espaço possui mais de três dimensões, as três espaciais conhecidas mais a dimensão temporal, não foi a única concepção existente ao final do Séc. XIX e início do Séc. XX. A concepção de espaço-tempo de Einstein-Minkowski, nasceu em um contexto de época em que as discussões sobre as dimensões do espaço estavam em alta, em diversas áreas da cultura moderna no ocidente. Como foi possível perceber, até mesmo na Rússia, as discussões sobre a quarta dimensão se apresentaram como relevantes.

O complexo ambiente cultural deste período pode ser percebido, ao longo do texto, como um fértil terreno para diversas elaborações de cunho mais místico, filosófico e artístico. Não nos parece forçoso, depois destas discussões, inferir que as questões da quarta dimensão faziam parte de uma cultura de época, de um conceito que permeou diversas áreas do conhecimento humano e esteve presente em diferentes ambientes culturais. $\mathrm{O}$ que nos leva a reforçar a visão de que a ciência de uma época está sempre inserida em um contexto sociocultural mais amplo, nunca isolada em laboratório ou gabinetes de pesquisa. Obviamente, existem os elementos intrínsecos à ciência e que são próprios deste meio intelectual, teorias que se apoiam em outras teorias e em pesquisas experimentais para o desenvolvimento científico. No entanto, a visão de uma ciência neutra, ahistórica e desvinculada do contexto sociocultural não se sustenta.

Quanto à Filosofia do Hiperespaço, foi possível perceber que a concepção de quarta dimensão destes filósofos era de que tal dimensão se tratava da realidade da existência humana. Segundo eles, somos seres quadridimensionais e vivemos em um espaço de quatro dimensões. No entanto, nossa capacidade de perceber esta realidade é que é limitada, assim, sentimos diretamente apenas as três dimensões espaciais e o passar do tempo. O que devemos fazer é desenvolver nossas capacidades para percebermos a quarta dimensão e, assim, abrir nossa compreensão do mundo de forma mais ampla.

Esta dimensão extra não é de natureza temporal, como a da teoria de EinsteinMinkowski, mas é uma dimensão espacial extra-sensorial. Ainda assim, o tempo é um elemento importante no conceito de quarta dimensão. Tanto o tempo como o movimento seriam as formas como nossos aparelhos sensoriais "percebem" a interação de fenômenos quadridimensionais como o mundo tridimensional que nos é acessível. Uma ideia fortemente influenciada pelo conceito de noumenon de Kant.

Como vimos, tais filósofos assumiram uma postura fortemente antipositivista e antimaterialista e, como sugerido no parágrafo anterior, se aproximaram bastante do idealismo Kantiano e de Platão. Mas, no seu estágio mais avançado, relacionaram a quarta dimensão a temas mais místicos, espiritualistas, ocultistas e teosóficos. Uma possível conexão 
entre a quarta dimensão e o mundo "psíquico" (psicológico) da mente, em oposição ao "mundo físico", também foi proposta por eles, mais especificamente por Ourspensky.

Além das discussões científicas, históricas e culturais ligadas ao desenvolvimento do conceito de quarta dimensão, apresentamos também a proposta de abordagem interdisciplinar para um curso de Teoria da Relatividade Restrita. Este curso foi elaborado para ser aplicado em uma disciplina de Física Moderna 1, obrigatória no currículo de licenciatura em Física da instituição mencionada. A proposta ainda está em fase de elaboração e será aplicada no primeiro semestre do ano de 2020.

A conexão entre as discussões científicas, históricas e culturais, da primeira parte deste trabalho, com a proposta interdisciplinar que apresentamos, reside no fato de que o texto aqui apresentado faz parte do material didático elaborado para os alunos do curso a ser realizado. Desta forma, apresentamos as discussões a respeito da historiografia da ciência relacionadas à produção de textos mais adequados para o ensino. Tratamos dos cuidados necessários à transposição didática de textos históricos para textos didáticos e apresentamos, como exemplo, os textos já mencionados.

Em termos gerais, acreditamos que este estudo traz uma contribuição a mais para o entendimento do rico e complexo ambiente cultural do século XIX. Um século que mudou a face do mundo ocidental, tanto cientificamente como social e economicamente.

Entendemos que este trabalho também apresenta uma contribuição, ao menos, interessante para o ensino de Física em um curso de graduação. Nesse intuito, a nossa proposta, ainda a ser realizada, poderá imprimir nos alunos o sentimento de que é totalmente possível e efetivo abordar os temas de Física de forma interdisciplinar, mesmo nas disciplinas mais complexas. Esta atividade poderá servir de exemplo positivo para as futuras práticas pedagógicas destes futuros professores.

\section{Referências}

ARCHIBALD, R. C. Time as a fourth dimension. Bulletin of the American Mathematical Society, v. 20, n. 8, p. 409-412, 1914.

BARCEllos, M. E.; ZANETIC, J. Abrindo a Caixa Preta da Massa Energia. Atas do XVII SNEF, São Luis, 2007. Disponível em:

$<$ http://www.cienciamao.usp.br/dados/snef/_abrindoacaixapretadamass.trabalho.pdf $>$. Acesso em: 31 out. 2019.

BRAGDON, C. A Primer of Higher Space (The tourth Dimension). Rochester, New York: Manas Press, 1913.

BRAGDON, C. F. Man the Square: a Higher Space Parable. Rochester, N.Y.: Manas Press, 1912. 
BRAGDON, C. Projective Ornament. Rochester, N.Y.: Manas Press, 1915.

BURCH, G. B. The Philosophy of P. D. Ouspensky. The Review of Metaphysics, v. 5, n. 2, p. 247-268, 1951. Disponível em: <www.jstor.org/stable/20123259>.

CAMPOS, L. C. B. D. Kant e a Geometria. 2016. Dissertação (Mestrado em Filosofia) Universidade de Campinas, Instituto de Filosofia e Ciências Humanas, Campinas. p. 116.

CHEVAllard, Y. La Transposición Didáctica: Del Saber Sabio al Saber Enseñado. Buenos Aires: Aique, 1991.

EUCLIDES. Os Elementos. Tradução: Irineu Bicudo. São Paulo: Editora UNESP, 2009.

EVES, H. Tópicos de História da Matemática para uso em sala de aula. Geometria. São Paulo: Atual, 1992. v. 3.

FERREIRA, J. M. H. Johann Zöllner: Fourth Dimention and Spiritual Phenomena in the end of Nineteenth Century. Circumscribere: International Journal for the History of Science, v. 3, p. 20-42, março 2008.

FORATO, T. C. M.; MARTINS, R. D. A.; PIETROCOLA, M. Prescrições Historiográficas e Saberes Escolares: Alguns Desafios e Riscos. In: ENCONTRO NACIONAL DE PESQUISA EM ENSINO DE CIÊNCIAS, VII, 2009, Florianópolis. Florianópolis: [s.n.]. 2009.

GALISON, P. L. Minkowski's space-time: from visual thinking to the absolute world. Historical Studies in the Physical Sciences, v. 10, p. 85-212, 1979.

GALISON, P. Os Relógios de Einstein: o Lugar do Tempo. Revista Ciência e Ambiente, Rio de Janeiro, v. 30, p. 7-34, 2005.

GIL PÉREZ, D. et al. Para uma imagem não deformada do trabalho científico. Ciência \& Educação, v. 7, n. 2, p. 125-153, 2001.

GREENBERG, M. J. Euclidean and non-Euclidean geometries: Development and history. 3. ed. New York: W. H. Freeman and Company, 1994.

GUERRA, A.; REIS, J. C.; BRAGA, M. Abordagem Cultural da Física: Discussão sobre o uso de linguagens diferenciadas no Ensino de Ciências. Enseñanza de las Ciencias, v. extra, p. 1686-1690, 2013. 
HENDERSON, L. D. The Fourth Dimension and Non-Euclidean Geometry in Modern Art. Revised edition. ed. Cambridge, Massachusetts, London, England: The MIT Press, 2013.

HENDERSON, L. D. X Rays and the Quest for Invisible Reality in the Art of Kupka, Duchamp, and the Cubists. Art Journal, v. 47, n. 4, Revising Cubism, p. 323-340, winter 1988.

HINTON, C. H. A New Era of Thought. [S.1.]: S. Sonnenschein \& Company, 1888.

HINTON, C. H. The Fourth Dimension. Londres: G. Allen \& Unwin Ltd, 1912. Disponível em: <https://archive.org/details/fourthdimension00hintarch/page/n3>. Acesso em: 19 mai. 2019.

JAMMER, M. Conceitos de espaço: a história das teorias do espaço na física. Rio de Janeiro: Contraponto, Editora PUC-Rio, 2010.

KANT, I. Crítica da Razão Pura. 4. ed. Petrópolis: Vozes, 2018.

MARTINS, A. F. P. História e Filosofia da Ciência no Ensino: Há Muitas Pedras Nesse Caminho. Caderno Brasileiro de Ensino de Física, v. 24, n. 1, p. 112-131, 2007.

MARTINS, L. A.-C. P. História da Ciência: Objetos, Métodos e Problemas. Ciência \& Educação, v. 11, n. 2, p. 305-317, 2005.

MARTINS, R. A. Como distorcer a física: considerações sobre um exemplo de divulgação científica 2-Física Moderna. Caderno Brasileiro de Ensino de Física, v. 15, n. 3, p. 265-300, 1998.

MARTINS, R. D. A. A fundamentação histórica da lei da inércia: um exemplo de conflito entre educadores e historiadores da ciência no uso da História da Ciência no Ensino de Física. In: CAMARGO, S. E. A. C. Controvérsias na pesquisa em ensino de física. São Paulo: Livraria da Física, 2014. p. 143-159.

MARTINS, R. D. A. A origem histórica da Relatividade Especial. São Paulo: Editora Livraria da Física, 2015.

MARTINS, R. D. A. O éter e a óptica dos corpos em movimento: a teoria de Fresnel e as tentativas de detecção do movimento da terra, antes dos experimentos de Michelson e Morley 
(1818-1880). Caderno Brasileiro de Ensino de Física, Florianópolis, v. 29, n. 1, p. 52-80, abr. 2012.

MCCOMAS, W.; ALMAZROA, H.; CLOUGH, M. P. The nature of science in science education: an introduction. Science \& Education, v. 7, p. 511-532, 1998.

MILLER, A. I. Albert Einstein's Special Theory of Relativity: Emergence (1905) and Early Interpretation (1905-1911). New York: Springer-Verlag New York, 1998.

MINKOWSKI, H. Space and Time: Minkowski's papers on relativity. Montreal: Minkowski Institute Press, 2012.

MORA, J. F. Dicionário de filosofia. São Paulo: Edições Loyola, 2001. v. 1.

MORIN, E. Introdução ao Pensamento Complexo. Porto Alegre: Sulina, 2005.

MOURA, C. B.; GUERRA, A. Reflexões sobre o processo de construção da ciência na disciplina de química: um estudo de caso a partir da história dos modelos atômicos. Revista Electrónica de Investigación em Educación em Ciencias, v. 11, n. 2, p. 64-77, dez. 2016.

OUSPENSKY, P. D. Tertium Organum. 2. ed. New York: Manas Press, 1922.

REIS, J. C.; GUERRA, A.; BRAGA, M. Ciência e arte: relações improváveis? História, Ciências, Saúde-Manguinhos, v. 13, p. 71-87, 2006.

REIS, U. V. D.; REIS, J. C. Os conceitos de espaço e de tempo como protagonistas no Ensino de Física: um relato sobre uma sequência didática com abordagem histórico-filosófica. Caderno Brasileiro de Ensino de Física, Florianópolis, v. 33, n. 3, p. 744-778, dez 2016.

ROSENFELD, B. A. A History of Non-Euclidean Geometry: Evolution of the Concept of a geometric space. Tradução: Abe Shenitzer. New York: Springer-Verlag, 1988.

SCHMIEDECKE, W. G.; PORTO, P. A. Uma abordagem da história da energia nuclear para a formação de professores de Física. Revista Brasileira de História da Ciência, Rio de Janeiro, 7, n. 2, p. 232-241, 2014.

SCOTT, W. Minkowski's Modern World. Minkowski Space-time: A Hundred Years Later, 2010. p. 43-61. 
SILVA, A. P. B. D. O desenvolvimento das mecânicas não-euclidianas durante o século XIX. 2006. Tese (Doutorado em Ciências) - Universidade Estadual de Campinas, Instituto de Fisica Gleb Wataghin, Campinas, SP. p. 131.

SOMMERVILLE, D. Bibliography of Non-Euclidean Geometry: including the theory of parallels, the foundations of geometry, and space of $n$ dimensions. London: London Pub. by Harrison for the University of St. Andrews, 1911. Disponível em: $<$ https://archive.org/details/bibliographyofno00sommuoft/page/n4>. Acesso em: 11 out. 2019.

ZANETIC, J. Física Também é Cultura. 1989. Tese (Doutorado em Educação) - Faculdade de Educação, USP, São Paulo. p. 160.

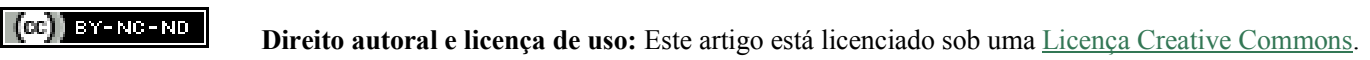

